\title{
Vapor Pressure and Fixed Points of Oxygen and Heat Capacity in the Critical Region
}

\author{
By Harold J. Hoge
}

\begin{abstract}
Vapor-pressure measurements on oxygen covering the entire range from the triple point to the critical point are reported. By measuring short sections of isotherms, the critical temperature and pressure were found to be $154.78^{\circ} \mathrm{K}$ and $50.14 \mathrm{~atm}$, respectively. The triple point temperature and pressure were found to be $54.363^{\circ} \mathrm{K}$ and $1.14 \mathrm{~mm} \mathrm{Hg}$ respectively. The two solid-solid transitions were found to be at $43.80_{0}^{\circ}$ and $23.886^{\circ} \mathrm{K}$ respectively. Measurements were made of the heat capacity of oxygen in the critical region at six different filling densities. A comparison of the temperature scales of three different laboratories is made, based upon reported values of the fixed points of hydrogen, nitrogen, and oxygen.
\end{abstract}

\section{Introduction}

This Bureau has maintained since 1939 a provisional temperature scale $[1]^{1}$ covering the range $11^{\circ}$ to $90^{\circ} \mathrm{K}$. This scale was based on a group of seven resistance thermometers, two of which have since suffered accidents that caused them to be removed from the group. ${ }^{2}$ The initial impetus for the work now being reported was a desire to relate this provisional temperature scale (PTS) to the properties of pure materials such as oxygen, so that the scale could be maintained without reference to the preservation of the original group of thermometers. Oxygen was chosen because its boiling point defines the lower limit of the International Temperature Scale (ITS) [2], and because the triple point and the two solid-solid transitions gave promise of being usable fixed points.

We have for some time been aware that the ITS and the PTS maintained by this Bureau do not join as smoothly (at $90.19^{\circ} \mathrm{K}$ ) as would be desirable. It seems likely that the two scales cannot be brought into agreement with the thermodynamic scale without modifications of both.

\footnotetext{
${ }_{1}$ Figures in brackets indicate the literature references at the end of this paper.

2 This group has recently been supplemented by 6 new thermometers carefully compared with members of the original group. The new thermometers all belong to a large group of thermometers recently made by the Leeds and Northrup Co. from the same piece of wire, at the suggestion of the Conference on Low Temperature Calorimetry of the American Chemical Society.
}

The vapor pressure data above $90.19^{\circ} \mathrm{K}$ will be useful when the time for modification of the two scales arrives. The vapor pressure of oxygen above $1 \mathrm{~atm}$ was not as well known as that of many other common gases. The last major investigation was by Dodge and Davis [3] in 1927 and went only to $21.47 \mathrm{~atm}$. Prior to that the best values were probably those reported by Onnes, Dorsman, and Holst [4] in 1914. The ITS was not employed in either investigation. Hence it was decided to extend the present measurements all the way to the critical point, using a modern high-purity platinum resistance thermometer calibrated on the ITS. Some highpressure heat-capacity measurements were made to test the value of calorimetry in mapping the critical region and determining the critical temperature. The critical point was located by measurement of short sections of isotherms ( $p$ versus $V$ ).

The work now being reported was begun in 1942. It was laid aside during the war and has been completed since the war. The primary purpose of defining the provisional temperature scale covering the range $11^{\circ}$ to $90^{\circ} \mathrm{K}$ in terms of the vapor pressures and fixed points of pure materials is only partially accomplished by the present work. Additional fixed points are needed, especially below $40^{\circ} \mathrm{K}$. Work on nitrogen and perhaps neon would help to complete the picture, and it is 
hoped that this can be carried out in the not too distant future.

\section{Apparatus}

The apparatus used in the 1942 measurements was a small adiabatic calorimeter originally used by Brickwedde and Scott in their investigations of HD. This calorimeter was similar in general design to the one described by Scott et al [5] except that it was much smaller. The vapor pressure was transmitted to the manometer through a small filling tube. The determinations of solidsolid transition temperatures were made in this apparatus; also some triple-point measurements and most of the vapor-pressure measurements below $1 / 10$ atm. With this apparatus both oil and mercury manometers were used.

The apparatus used in the measurements made since the war is shown schematically in figure 1 . The low-pressure apparatus (upper half of fig. 1) was of glass, with a conventional mercury-in-glass manometer, which was read on a mirror-backed glass scale. Pressures up to about $1 \mathrm{~m} \mathrm{Hg}$ were read directly on this scale, and higher pressures up to about $1.7 \mathrm{~atm}$ were read by opening the stop cock to the atmosphere, and adding the reading of the barometer to the reading of the manometer. A flask of approximately 3-liter capacity marked calibrated volume was used for measuring the quantity of $\mathrm{O}_{2}$ admitted to the apparatus. One of the condensing tubes was used to collect the $\mathrm{O}_{2}$ as it was prepared by decomposition of $\mathrm{KMnO}_{4}$. The other

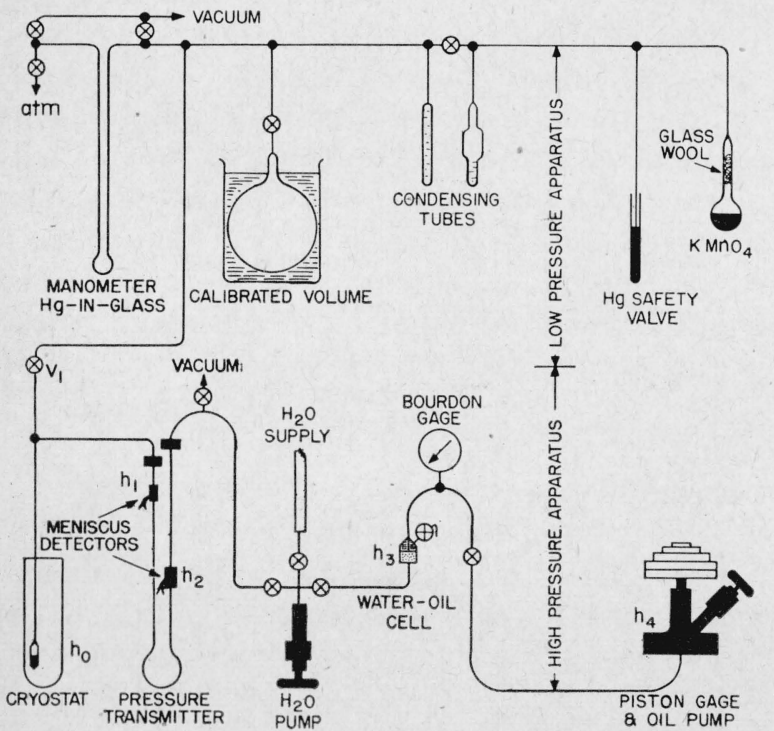

Figure 1. Apparatus used in most of the measurements. was useful in certain cases where oxygen was to be transferred from one part of the apparatus to another.

The apparatus capable of withstanding high pressure (lower half of fig. 1) consisted of a cryostat, a pressure transmitter, a water pump, a water-oil cell, a Bourdon pressure gage, and finally a piston gage. Pressure exerted by $\mathrm{O}_{2}$ in the cryostat was communicated by vapor of the sample itself to mercury contained in the pressure transmitter. Thence it was transmitted thru mercury from the first meniscus to the second, then thru water to the water-oil cell, and finally thru oil to the piston gage.

Cryostat. Some details of the equilibrium chamber and its immediate surroundings are shown in figure 2 . The equilibrium chamber was made by boring out a short section of pure nickel $\operatorname{rod}(5 / 8$ in. outside diameter) closing the lower end with a nickel cap and connecting the upper end to a heavy-wall nickel tube (1/8 in. by $1 / 16$ in.), which transmitted the vapor pressure to the measuring system. After assembly with silver solder the equilibrium chamber was inserted into a well in the heavy copper block and soft-soldered in place. The heavy copper block contained also a well for the resistance thermometer. Thermal contact between the thermometer and the block was obtained with stopcock grease. Actually there were two equilibrium chambers and two thermometer wells spaced alternately at $90^{\circ}$ intervals about the axis of the block, but only one thermometer and one well were used in the present experiments. For convenience in representation, figure 2 shows a thermometer in the position actually occupied by the second equilibrium chamber. The copper block was held firmly in place by a short length of $1 / 2$-in. monel tubing. The vapor-pressure tubes passed through slots in this tube. All three of the tubes were soldered to a copper bushing, which fit snugly into a sleeve that formed part of the shield. In figure 2 the sleeve and bushing appear as a single piece of metal. Stopcock grease was placed in the joint between them to improve thermal contact. The weight of the copper-block assembly was carried by the two vapor-pressure tubes. For the insertion or removal of thermometers, the container and the thermal shield could be removed and the vapor-pressure tubes unsoldered at another sleeve and bushing above the cryostat, 


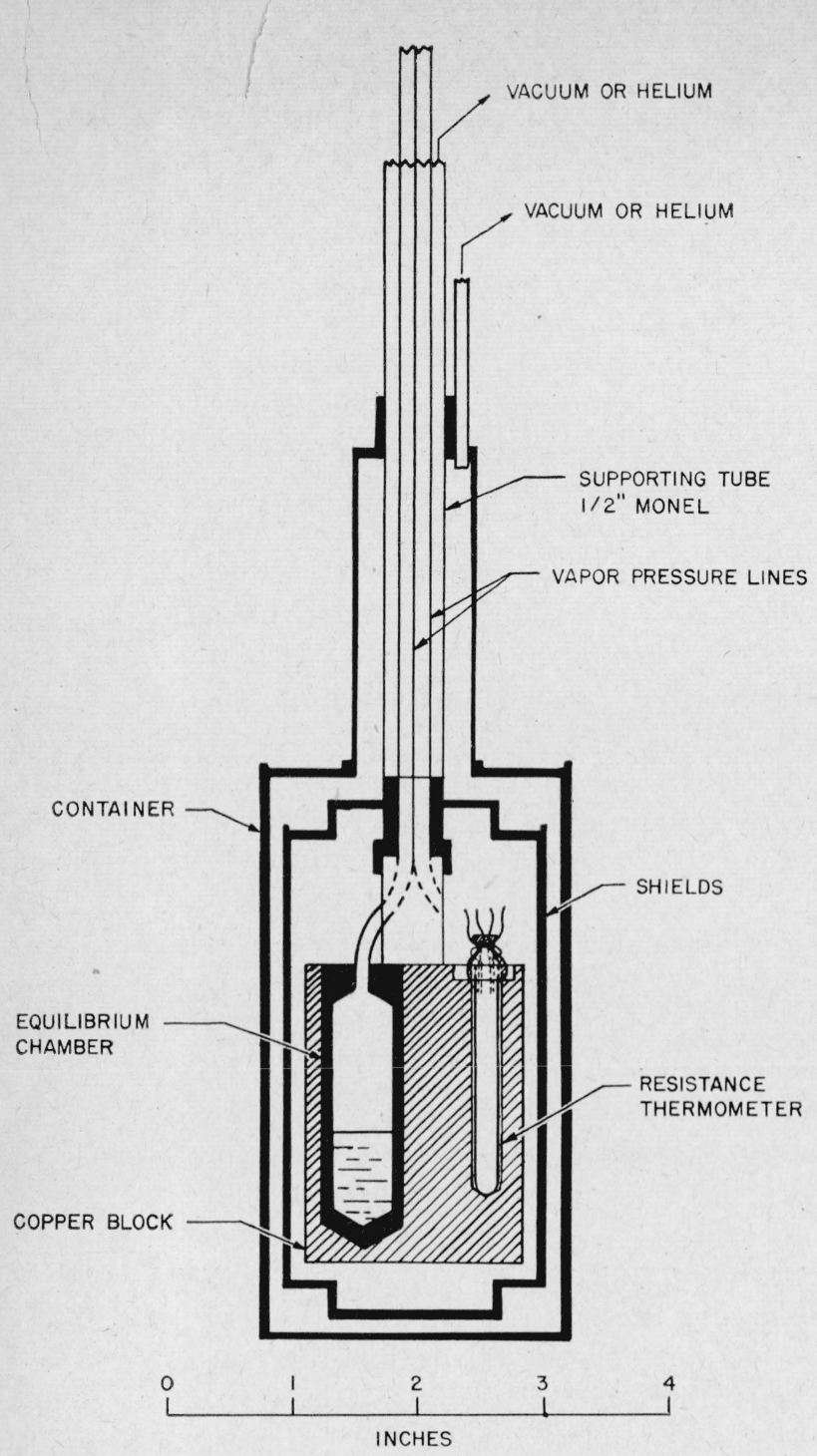

Figure 2. Cryostat, showing equilibrium chamber and resistance thermometer.

Drawn to scale.

after which the block assembly could be lowered several inches.

The shield system was rather heavy $(1 / 16$-in. wall) and was vacuum tight. This permitted the space between the shield and the container to be evacuated while a small amount of helium was left inside the shield and in the supporting tube that contained the vapor pressure lines. By varying the helium pressure, the temperature of the heavy vapor pressure lines could be controlled without the use of unduly large heaters. The system worked satisfactorily but was less convenient to adjust than a system involving only electrical heaters. No advantage was anticipated from having helium around the block itself, but this simplified the problem of getting the leads to the block. However, when the measurements were about three-fourths completed a leak developed in the resistance thermometer. This would have prevented further measurements had it not been possible to operate with the block in an atmosphere of helium. The helium was of course a disadvantage in heat-capacity measurements.

The supporting tube carried the shield at its lower end. For a distance of about 2.5 in. ${ }^{3}$ above the shield it was protected from the refrigerating bath by a 1-in. tube that was essentially a continuation of the container. "A heater was wound on the outside of the protected section of the supporting tube. Two thermel (thermel=thermocouple or thermopile) junctions were placed on the vapor pressure lines, but no heater was wound on them. In addition a six-power difference thermel was used in controlling the temperature of the tubes and shield. Two junctions were on the tubes, one on the top of the shield, two on the side, and one on the bottom. They could be used as a single pile; also certain junctions and subgroups could be observed separately The bottom, top, side, and tube heaters were all in series. The first three were controlled as a unit, with only occasional adjustment of shunts across the bottom and top heaters. It was found impractical to include the tube heater in the group.

To permit rough heat-capacity measurements, a heater was wrapped on the outside of the block. One of the potential terminals for power measurement was located where the current lead reached the block; the other was located near the top of the short section of thin monel tubing that helped to support the copper block.

Meniscus detectors. The pressure transmitter used during the latter part of the measurements was a $1 / 2$-in. stainless steel tube partially filled with mercury. Since the positions of the menisci could not be observed visually, a method was employed that involved the detection of the positions of nickel floats by means of an inductance bridge. The scheme and detecting circuit were designed for us by Maurice L. Greenough. The floats were pure nickel cylinders $(5 / 16$-in. inside diameter, 0012

\footnotetext{
3 A length $25 \%$ greater wouid have been better.
} 
in. wall) machined from larger stock so as to leave four projections at each end to keep the floats centered inside the stainless steel tube. When placed on a mercury surface the floats did not sink, but were held entirely above the mercury by surface tension. Mercury tended to wet them on prolonged contact. This was controlled by oxidizing the floats in an oxygen flame before use.

Each detecting unit was a center-tapped inductance coil of AWG38 enameled copper magnet wire. The two halves were wound on a common lucite form, which slid freely up and down the stainless steel tube. Each half had an inductance of about 0.495 henry and a resistance of about $825 \mathrm{ohms}$, and occupied a space $1 / 2$ in. long, with inside and outside diameters of $2 \frac{1}{32}$ and $1 \frac{1}{8} \mathrm{in}$., respectively. The output of a beat-frequency oscillator was applied across either detecting unit with the center taps of the oscillator and the detecting unit connected together through a microammeter and a germanium rectifier so as to form an inductance bridge. The bridge was balanced by moving the detector until the float was midway between the two halves of the detector coil. Accuracy of the detection is discussed later.

Diaphragm cell. The pressure transmitter just described was used only in the later measurements. In the earlier measurements a diaphragm cell was used that was similar to the one described by Osborne, Stimson, Fiock, and Ginnings [6]. The diaphragm was of pure nickel 0.003 in. thick, clamped between two cylindrical blocks of monel metal about 4 in. in diameter. The adjacent surfaces of the blocks were hollowed out to a maximum depth of 0.005 in., so that the center of the diaphragm was free to move through a distance of $0.010 \mathrm{in}$. The dished-out areas had a diameter of $2.36 \mathrm{in}$. This was larger than the cell used by Osborne et al., for the purpose of obtaining higher sensitivity, but the larger size seemed to be more difficult to assemble vacuum tight. It was clamped by twelve $1 / 4$-in. bolts. Larger bolts, and a working diameter of perhaps $1 \frac{3 / 4}{3}$ in. would have reduced the troubles encountered. The cell was assembled in such a way as to stretch the diaphragm slightly just before it was permanently clamped between the cell blocks. This was done by making the diaphragm larger than would otherwise have been necessary and first clamping it at its periphery so as to hold it in a plane slightly above the lower cell block. When the upper cell block was placed in position it pushed the central portion of the diaphragm out of its original plane before clamping it against the lower block. At the center of each block a 0.014-in. hole was drilled. Through one of these the pressure of oxygen vapor was applied to the lower side of the diaphragm. The upper side of the cell was connected to a line leading to the piston gage. This line contained two glass tubes, one immediately above the diaphragm in which the position of a water meniscus was observed; and another where the position of the oil meniscus was observed. The line connecting the tops of the two glass tubes contained a tee for admitting helium gas to the appropriate pressure. Water filled the space above the diaphragm and the line leading from it, so that the position of the diaphragm was registered by the height of the water column in the glass tube. The diaphragm cell worked satisfactorily for a period of months. After this it received very little use while the heat-capacity measurements were in progress. When vaporpressure measurements were resumed the diaphragm was found to be unusable, presumably because its position of equilibrium was no longer in the middle of the cell. The pressure transmitter shown in figure 1 was then substituted for it, with the addition of the water pump and wateroil cell. When both apparatuses were working properly they gave results of comparable accuracy. The one shown in figure 1 was easier to use, however, and had the advantage that at higher pressures the quantity of $\mathrm{O}_{2}$ in the cryostat could be varied over a large range. This was accomplished by changing the positions of the menisci and thus varying the volume in the transmitter that was occupied by $\mathrm{O}_{2}$ gas at high pressure.

Water pump and water-oil cell. The water line was introduced between the oil and the mercury for reasons of safety. It could be omitted from an apparatus where the possibility of $\mathrm{O}_{2}$-oil explosions was not present. The water pump was constructed much like an ordinary packed needle valve with a $5 / 8$-in. polished bronze plunger replacing the needle. The plunger had a travel of $2 \frac{1}{2}$ in., the thread on the stem was $1 / 2$ in. -13 , and the $4 \frac{3}{8}-$ in . hand wheel was reasonably easy to turn up to pressures of $50 \mathrm{~atm}$. The water-oil cell contained a valve for bleeding the line and thus making sure of the position of the water-oil meniscus.

Piston gage. The piston gage used was number 
2-A-30213, previously described by Meyers and Jessup [7]. It had a range of about $100 \mathrm{~atm}$. The effective area of the piston was $1.0065_{3}$ $\mathrm{cm}^{2}$ according to data furnished by Meyers. Since it is known that pistons occasionally suffer appreciable changes in diameter, the gage was checked by comparing it with another gage of the group described by Meyers and Jessup (number 5-D-30778). The two gages agreed to better than a part in 5,000.

\section{Preparation and Purity of Samples}

Three different samples of $\mathrm{O}_{2}$ were used. The first sample was used in all the 1942 measurements, the second in all subsequent measurements prior to July 1, 1947, and the last sample in all later measurements. All were prepared from $\mathrm{KMnO}_{4}$. The first sample was fractionally distilled and tested by comparison of the vapor pressures of various fractions. No improvement in purity was noted. The last two samples were not distilled, but at the time of preparation the first and last portions of the oxygen generated were discarded. The possibility that the concentration of $\mathrm{O}^{18}$ in the samples would be affected by the distillation or the method of preparation was considered. Stedman [8] was able to increase the concentration of $\mathrm{O}^{18}$ from the normal 1 part in 500 to 1 part in 400 by running a $16-\mathrm{ft}$ distillation column for $27 \mathrm{hr}$. The vapor pressure of the pure heavy isotope is probably only 1.5 percent less than that of the normal mixture. Hence it seems very unlikely that changes in isotopic composition could have any appreciable effect on the present measurements.

As some have had difficulty in preparing pure oxygen from $\mathrm{KMnO}_{4}$, a few of the details of the technique used will be described. Except for minor modifications the procedures are those described by Scott [9]. A mass of $\mathrm{KMnO}_{4}$ equal to about ten times ${ }^{4}$ the required mass of oxygen is placed in a glass bulb, confined with a plug of glass wool and sealed to the system. The bulb should be only about half full as the crystals swell and turn to powder during the reaction. The glass wool prevents powder from contaminating the rest of the system. A furnace is placed around the bulb, and the system is evacuated overnight or longer with the temperature slightly above

\footnotetext{
1 According to the reaction $2 \mathrm{KMnO}_{4}+$ heat $\rightarrow \mathrm{MnO}_{2}+\mathrm{K}_{2} \mathrm{MnO}_{4}+0_{2}$, it takes
} $9.88 \mathrm{~g}$ of $\mathrm{KMnO}_{4}$ to make $1 \mathrm{~g}$ of $\mathrm{O}_{2}$ or $11.3 \mathrm{~g}$ to make $1 \mathrm{~cm}^{3}(1.14 \mathrm{~g})$ of liquid $\mathrm{O}_{2}$. $100^{\circ} \mathrm{C}$. The temperature is then raised fairly rapidly to, say, $160^{\circ} \mathrm{C}$ and then more slowly until a noticeable evolution of $\mathrm{O}_{2}$ is registered by the pressure gage of the vacuum system. This will occur at about $200^{\circ} \mathrm{C}$. The vacuum pump is left. running, and the temperature is slowly raised until the reaction chamber is thoroughly flushed. The rate of generation of $\mathrm{O}_{2}$ is estimated by closing the line to the pump temporarily and noting the rate of rise of pressure. After it is judged that 5 or 10 percent of the material has reacted, the pump line is closed and collection of the sample is begun. The reaction accelerates as it proceeds, and is accompanied by decrepitation of the $\mathrm{KMnO}_{4}$ crystals. It seems plausible that any adsorbed gases will be gotten rid of more completely if a small amount of decrepitation occurs before collection of the sample is started. The furnace temperature should be rather carefully controlled as the reaction gets under way. Generally the furnace temperature need not be raised above $230^{\circ}$ C. Collection of the sample is observed in one of the condensing tubes, and when the reaction is judged to be about 80 percent complete the remainder of the $\mathrm{O}_{2}$ is either discarded or collected in the other tube.

There was no indication in the vapor-pressure data of any difference in the purity of the three samples. Melting-point data were taken on the first and last samples. The equilibrium temperature was plotted versus the reciprocal of $F$, the fraction of the sample melted, and the slope of a straight line drawn through the points was measured. This slope is the coefficient of $1 / F$ in the usual formula for freezing point depression: $T_{f}-$ $T=\left(x R T_{f}^{2} / L_{f}\right)(1 / F)$. Using Giauque and Johnston's [10] value for $L_{f}\left(106.3\right.$ cal $\left.\mathrm{mole}^{-1}\right)$ and $54.363^{\circ} \mathrm{K}$ for $T_{f}$, values of $x$, the mole fraction of impurity, were computed. For the first sample $x$ was found to be $2 \times 10^{-7}$, with an uncertainty in $x$ of about 50 percent. The graph for the third sample gave the same value of $x$, but the uncertainty was larger - of the order of 100 percent. No melting-point data were taken on the second sample, but it is thought to have been of the same purity as the other two.

\section{Vapor Pressure}

Measurements. The vapor-pressure data are given in table 1 . One column of this table gives the type of pressure-measuring system employed. 
This was either a simple oil manometer (oil), a simple mercury manometer $(\mathrm{Hg})$, a mercury manometer reading the excess above barometric pressure $(\mathrm{HgB})$, a piston gage with pressure transmitted to it through a diaphragm cell (PGD), or a piston gage with pressure transmitted to it through the mercury-filled $U$-tube shown in figure 1 (PGHg). The method used at each point is indicated in one of the columns of table 1.

TABLE 1. Observations of the vapor pressure of $\mathrm{O}_{2}$

The column headed $\Delta p$ contains deviations of the observed values from table 2

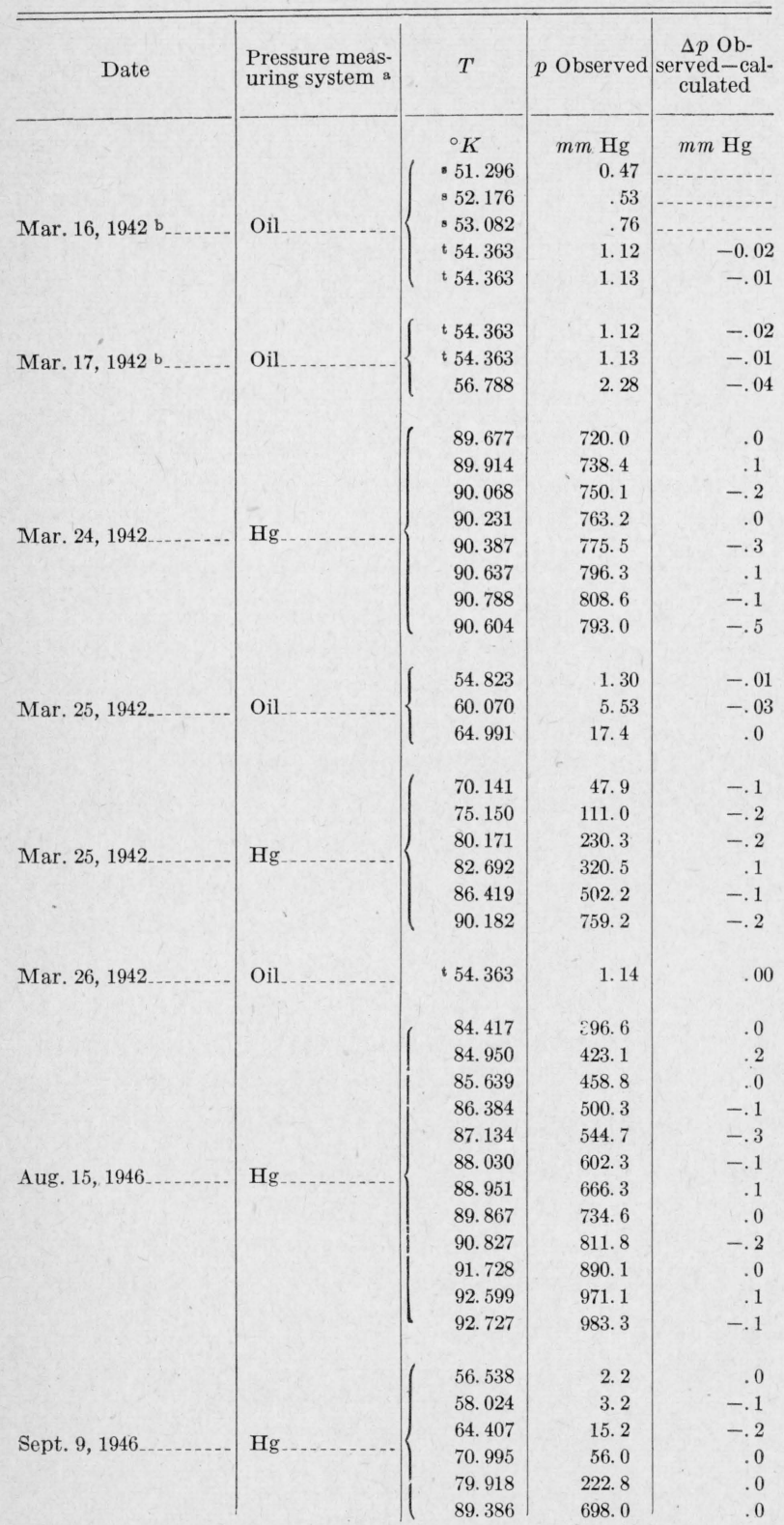

TABLE 1. Observations of the vapor pressure of $\mathrm{O}_{2}-$ Con.

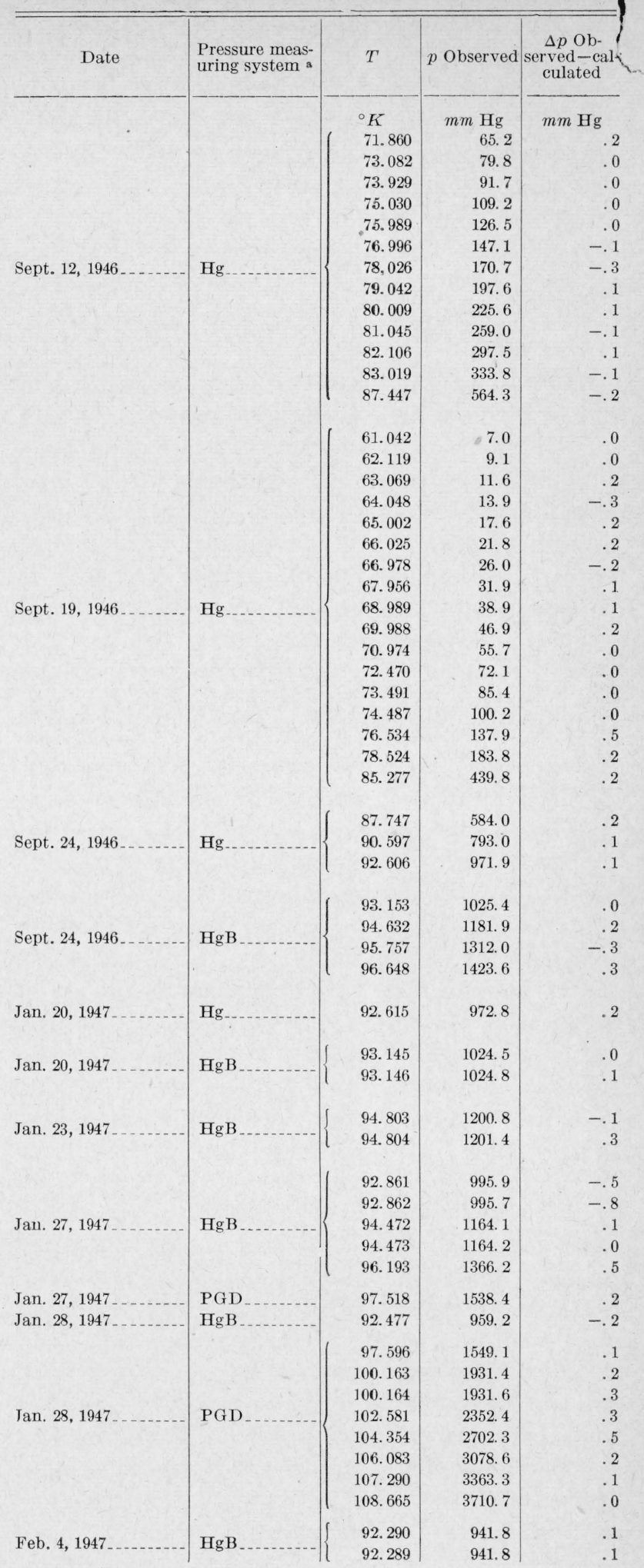


TABLE 1. Observations of the vapor pressure of $\mathrm{O}_{2}-\mathrm{Con}$.

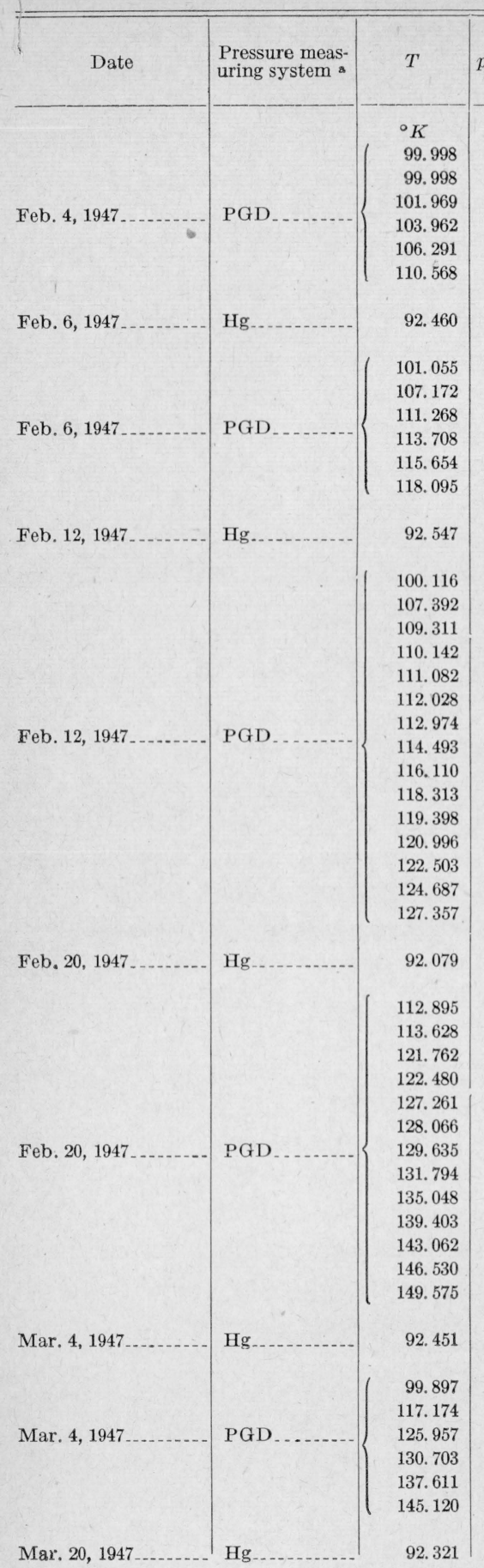

0.1

\begin{tabular}{|c|c|}
\hline$p$ Observed & $\begin{array}{c}\Delta p \mathrm{Ob}- \\
\text { served-cal- } \\
\text { culated }\end{array}$ \\
\hline$m m \mathrm{Hg}$ & $m m \mathrm{Hg}$ \\
\hline 1904.0 & -.7 \\
\hline 1904.5 & -.2 \\
\hline 2239.1 & -.5 \\
\hline 2620.6 & -.7 \\
\hline 3124.3 & -1.9 \\
\hline 4231.7 & -2.9 \\
\hline 957.8 & 0.0 \\
\hline 2078.8 & -.4 \\
\hline 3333.0 & -1.5 \\
\hline 4438.8 & -1.5 \\
\hline 5214.9 & 0.6 \\
\hline 5898.6 & 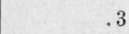 \\
\hline 6846.8 & .8 \\
\hline 966.0 & \\
\hline 1924.4 & . \\
\hline 3388.7 & . \\
\hline 3883.1 & 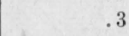 \\
\hline 4113. 5 & . \\
\hline 4385.3 & . \\
\hline 4672.4 & . \\
\hline 4972.6 & . \\
\hline 5483.4 & . \\
\hline 6068.8 & . \\
\hline 6936.3 & . \\
\hline 7394.7 & . \\
\hline 8110.4 &. \\
\hline 8829.0 &. \\
\hline 9951.3 & . \\
\hline 11459 & 2 \\
\hline 922.4 & 0.3 \\
\hline 4945.7 & -.6 \\
\hline 5186.9 & -.4 \\
\hline 8468.4 & -1.1 \\
\hline 8816.6 & -1.2 \\
\hline 11400 & 0 \\
\hline 11883 & 0 \\
\hline 12866 & 0 \\
\hline 14312 & 0 \\
\hline 16709 & 1 \\
\hline 20351 & 0 \\
\hline 23833 & 1 \\
\hline 27521 & 2 \\
\hline 31103 & 0 \\
\hline 956.4 & -0.5 \\
\hline 1888.1 & -.4 \\
\hline 6475.3 & -1.2 \\
\hline 10646 & -2 \\
\hline 13566 & -1 \\
\hline 18789 & -1 \\
\hline 25973 & 1 \\
\hline 944.8 & 0. \\
\hline
\end{tabular}

TABLE 1. Observations of the vapor pressure of $\mathrm{O}_{2}-\mathrm{Con}$.

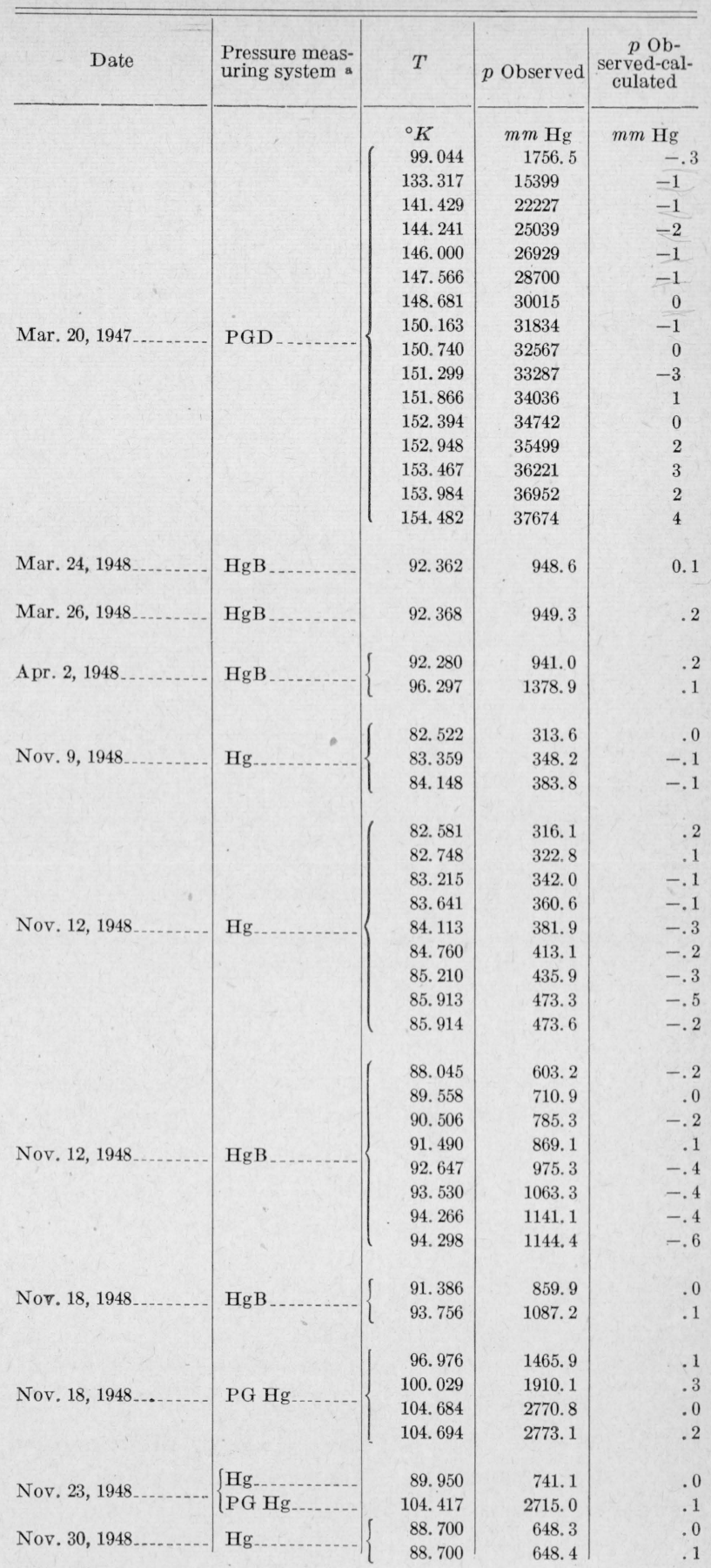

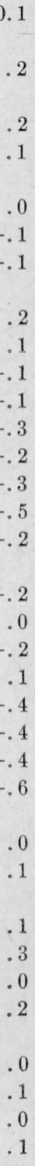

See footnotes at end of table. 
TABLE 1. Observations of the vapor pressure of $\mathrm{O}_{2}-\mathrm{Con}$.

\begin{tabular}{|c|c|c|c|c|}
\hline Date. & $\begin{array}{l}\text { Pressure meas- } \\
\text { uring system a }\end{array}$ & $T$ & $p$ Observed & $\begin{array}{c}p \text { Ob- } \\
\text { served-cal- } \\
\text { culated }\end{array}$ \\
\hline Dec. 17,1948 & PG Hg & $\begin{array}{l}{ }^{\circ} K \\
131.540 \\
141.159 \\
146.974 \\
150.294 \\
151.301 \\
152.574 \\
153.553\end{array}$ & $\begin{array}{c}m m \mathrm{Hg} \\
14140 \\
21973 \\
28022 \\
31999 \\
33291 \\
34986 \\
36339\end{array}$ & $\begin{array}{r}m m \text { H } \\
4 \\
2 \\
1 \\
-1 \\
-1 \\
1 \\
-1\end{array}$ \\
\hline Dec. $21,1948 \ldots$ & $\mathrm{Hg} \mathrm{B}$.. & $\begin{array}{l}87.887 \\
91.526 \\
93.770 \\
93.769\end{array}$ & $\begin{array}{r}593.1 \\
872.3 \\
1089.0 \\
1088.5\end{array}$ & $\begin{array}{r}0.2 \\
.2 \\
.4 \\
.0\end{array}$ \\
\hline Dec. 21,1948 & $\mathrm{PG} \mathrm{Hg}$ & $\left\{\begin{array}{l}109.930 \\
124.725 \\
140.329\end{array}\right.$ & $\begin{array}{l}4053.1 \\
9971.3 \\
21196\end{array}$ & $\begin{array}{c}-.3 \\
-.2 \\
2\end{array}$ \\
\hline Dec. 29,1948 & $\mathrm{PG} \mathrm{Hg}$. & $\begin{array}{r}135.592 \\
140.615 \\
144.396 \\
148.029 \\
151.145 \\
154.188 \\
154.580 \\
154.760\end{array}$ & $\begin{array}{l}17133 \\
21458 \\
25203 \\
29239 \\
33086 \\
37240 \\
37816 \\
38079\end{array}$ & $\begin{array}{r}-1 \\
-1 \\
-1 \\
-2 \\
-3 \\
-3 \\
1 \\
0\end{array}$ \\
\hline
\end{tabular}

\footnotetext{
a Pressure-measuring systems are identified as follows: Oil=oil manometer; $\mathrm{Hg}=$ mercury manometer, one side evacuated; $\mathrm{HgB}=$ mercury manometer, one side open to atmosphere, reading added to barometer reading; $\mathrm{PGD}=$ piston gage, with pressure transmitted through diaphragm cell; $\mathrm{PG} \mathrm{Hg}=$ piston gage with pressure transmitted through mercury as shown in figure 1 .

b Data taken on March 16 and 17, 1942 are less reliable than later data because of possibility of condensation in tube leading to manometer.

- Oxygen was solid at this temperature.

$t$ Triple point.
}

The oil manometer contained apiezon-B oil with a density $\rho\left(\mathrm{g} \mathrm{cm}^{-3}\right)=0.86022-0.00063(t-25)$ as determined from measurements at $20^{\circ}, 25^{\circ}$, and $30^{\circ} \mathrm{C}$ by the Capacity, Density, and Fluid Meters section of this Bureau. However, when the same pressure was read simultaneously on the oil manometer and the $\mathrm{Hg}$ manometer the pressures did not agree exactly, possibly due to solution of $\mathrm{O}_{2}$ in the oil. Densities given by the above equation were accordingly multiplied by 0.997 to bring the oil- and mercury-manometer data into agreement. The rate of diffusion of oxygen through the oil in the manometer appeared to be very slow; however, the vacuum side of the manometer was reevacuated frequently as a precautionary measure. All pressure measurements were reduced to standard $\mathrm{mm} \mathrm{Hg}$ ( $g=980.665, t=0^{\circ} \mathrm{C}$ ) assuming local gravity to be 980.10 .

Temperatures were measured by a capsuletype platinum resistance thermometer. Ther- mometer L3 was used in the 1942 measurements and L14 in all subsequent work. Thermometer L3 was one of the original group used to define the temperature scale below $90^{\circ} \mathrm{K}$, which this Bureau now maintains. Its calibration is discussed in reference [1]. Thermometer L14 was calibrated below $90^{\circ} \mathrm{K}$ by comparison with thermometers of this original group, and above $90^{\circ}$ on the ITS [2]. Resistances were measured on a Mueller resistance bridge.

Both the oil and the $\mathrm{Hg}$ manometers were read on mirror-backed calibrated glass scales. Where several observations were made at the same point, the vertical position of the scale was shifted slightly after each pair of readings. This has been found to increase the accuracy of the observations. In general an experimental point consisted of three manometer readings alternated with two resistance readings. Where the pressure was too high to be read on the $\mathrm{Hg}$ manometer alone it was necessary to read the barometer. Barometer readings are also required when a piston gage is used. Rather than read two instruments simultaneously it was found better to make barometer readings at more convenient times and to record the times of all readings. The barometer height was then plotted as a function of time, and appropriate values were read from the curve to add to the readings of the other instruments.

The procedure for taking data with the piston gage was different when the diaphragm cell was used than when the apparatus was employed as shown in figure 1 . With the diaphragm cell, the first step was to calibrate the diaphragm by finding the height of the water column in the glass tube above it as a function of the pressure difference across the diaphragm. This was done before almost every run, although the change in calibration was small and monotonic over the period of most of the measurements involving the diaphragm cell. To calibrate, a pressure near the lower limit of the piston gage $(\sim 900 \mathrm{~mm} \mathrm{Hg})$ was measured simultaneously by the manometer $(\mathrm{Hg}$ or $\mathrm{HgB}$ ) and by the piston gage (PGD). The two results were set equal to each other, with the pressure supported by the diaphragm appearing as an unknown quantity to be determined from the equation. After an observation the weight on the piston gage was changed by a few grams and conditions readjusted so that the diaphragm 
had moved slightly. A calibration consisted of five or ten such observations. Over a range of about $70 \mathrm{~mm}$ in the height of the water column the calibration was linear, with a change in water height of $1 \mathrm{~mm}$ corresponding to a pressure change of $0.95 \mathrm{~mm} \mathrm{Hg}$. To make measurements the temperature of the cryostat was raised to the desired value, helium was admitted to the line between the diaphragm and the piston gage until the diaphragm was near its equilibrium position. Then the valve to the piston gage was opened slightly and the weights adjusted until balance was obtained. The weights were then recorded and also the heights of the menisci in the water and oil sight glasses. Room temperature was recorded for use in computing the densities of the oil and water columns. After a pressure balance had been obtained, the weight on the piston gage was changed by 5 or $10 \mathrm{~g}$ and balance restored by changing the amount of oil or helium in the system. This caused the diaphragm to take up a new position, still in the linear range covered by the calibration. Another set of readings was then made. An experimental determination consisted of three sets of readings of the piston gage and diaphragm, alternated with four readings of the resistance thermometer.

The diaphragm worked satisfactorily in all measurements made in 1947 . When it was first used in 1948, however, the data did not agree among themselves or with the earlier data. The diaphragm cell was found to be unusable and was replaced by the pressure transmitter shown in figure 1. The cell could have been put back in service by replacing the diaphragm, but it was thought preferable to replace it with a different mechanism and thus obtain an independent check on the reliability of the data. The pressure transmitter shown in figure 1 was therefore used. The method of observing mercury meniscus positions is described in the section on apparatus. After the piston gage had been balanced and the weights recorded, a series of observations of thermometer resistance was begun. While one operator recorded resistances at 1-min intervals, the second operator simultaneously observed the heights of the mercury columns in each arm of the pressure transmitter. Temperatures were recorded for use in computing the density of the mercury, water, and oil through which the pressure was transmitted. The water-oil cell was bled occasionally to establish the position of the water-oil boundary in this cell. The valves were manipulated in such a way as to keep this position constant except for the compressibility of the oil and the leakage of oil past the piston. The density of the oil was not greatly different from the density of water. A 64-mm uncertainty in the height of the wateroil boundary would have been required to cause an error in pressure of $1 \mathrm{~mm} \mathrm{Hg}$.

The computation of pressures from piston-gage data requires a number of corrections to be made. The desired pressure $P$ is that at the liquid-rapor interface in the equilibrium chamber. This pressure is equal to the hydrostatic pressure due to all fluids in the transmitting line, plus the pressure exerted by the piston gage, plus the barometric pressure. That is

$$
P\left(\text { dyne } \mathrm{cm}^{-2}\right)=\int \rho g d h+\left(m_{0}+m\right)(g / a)+b,
$$

where $g$ is the acceleration of gravity, $m_{0}$ is the fixed mass of the piston, weight-carrier etc., $m$ is the mass of the weights added, $a$ is the effective area of the piston, and $b$ is the barometric pressure. The integral can be divided into several parts. Starting at the liquid-vapor surface we have first a column of $\mathrm{O}_{2}$ vapor. We integrate along the transmitting line, taking $d h$ positive upward. Referring now to figure 1 there is next a section of the line filled with mercury, then one filled with water and finally oil. Let $h_{0}, h_{1}, h_{2}, h_{3}$, $h_{4}$ be the respective heights of the phase boundaries between $\mathrm{O}_{2}$-liquid and $\mathrm{O}_{2}$-vapor, $\mathrm{O}_{2}$-vapor and $\mathrm{Hg}$, $\mathrm{Hg}$ and water, water and oil, oil and the base of the piston. Then the integral can be broken into the following parts

$$
\begin{aligned}
& \int \rho g d h=\int_{h_{0}}^{h_{1}} \rho\left(0_{2}\right) g d h+\rho(H g) g\left(h_{2}-h_{1}\right) \\
& +\rho \text { (water) } g\left(h_{3}-h_{2}\right)+\rho(\text { oil }) g\left(h_{4}-h_{3}\right) .
\end{aligned}
$$

All heights remain constant except $h_{1}$ and $h_{2}$, provided the apparatus remains undisturbed and the water-oil cell is properly bled. In the above formula, heights must be in centimeters if densities are in grams per cubic centimeter.

The correction for the hydrostatic pressure of oxygen vapor is quite small and was applied only at pressures above $1 \mathrm{~m} \mathrm{Hg}$. Many of the quantities entering into the correction had to be esti- 
mated-particularly the temperature distribution along the tube leading out of the cryostat. Other data were taken from the Mollier chart of Millar and Sullivan [11]. The correction ranged from about $0.1 \mathrm{~mm} \mathrm{Hg}$ at $1 \mathrm{~m} \mathrm{Hg}$ to about $6.5 \mathrm{~mm} \mathrm{Hg}$ at the critical point. Except near the latter point it was nearly proportional to the pressure. The correction was applied by increasing $\log _{10} P$ by values ranging from 0.00005 to 0.00007 , in the case of the $\mathrm{PG} \mathrm{Hg}$ measurements.

For the diaphragm cell (PGD) apparatus the correction for oxygen vapor was only slightly different. The equation for $P$ given above was modified, however, to take into account the changed arrangement of fluids in the transmitting line, and included a term for the pressure supported by the diaphragm.

To reduce piston-gage readings to std $\mathrm{mm} \mathrm{Hg}$ $\rho\left(\mathrm{Hg}, 0^{\circ} \mathrm{C}\right)$ was taken to be $13.59504 \mathrm{~g} \mathrm{~cm}^{-3}$ [12], and the values of local and standard gravity given earlier were used. The piston-gage oil had a density of $0.8680 \mathrm{~g} \mathrm{~cm}^{-3}$ at $20^{\circ} \mathrm{C}$. Variations in the density of water and oil with temperature were taken into account, although they were nearly negligible. Effect of pressure on the density of the oil was neglected. At $50 \mathrm{~atm}$, the density would probably be from 4 to 6 per mille greater than at $1 \mathrm{~atm}$ [13]. This would cause an error of only $0.1 \mathrm{~mm} \mathrm{Hg}$ in the PGD data, and would have still less effect on the PGHg measurements. The mercury column height $h_{2}-h_{1}$ was of course reduced to standard conditions.

Analysis of the data. A number of vaporpressure equations were used at various stages of the work. The procedure finally adopted, however, is the only one that will be described in detail. This procedure led to the preparation of table 2 , which gives $\log _{10} p$ at uniform intervals of $1 / T$ (or $2 / T)$. It is thought that interpolation in this table will be more rapid and convenient than evaluating any equation that might represent the data with comparable accuracy. The table gives logarithms of pressures in $\mathrm{mm} \mathrm{Hg}$, in atmospheres, and in pounds per square inch absolute. Since a change in units changes logarithms by a constant amount, a single column of differences suffices for all three columns of $\log _{10} p$. Values of all negative logarithms have been increased by 10 to keep the mantissa positive. The value of $T$ corresponding to each value of $1 / T$ is given in the table. However, interpo- lations in the table should be made in terms of the argument $1 / T$ (or $2 / T$ ) rather than in terms of $T$ if maximum accuracy is desired. For convenience of those who prefer engineering units, the argument in table 2 is given in units based on Rankine (Fahrenheit absolute) temperatures, as well as Kelvin temperatures.

The scattering of the experimental data, as well as the accuracy with which table 2 represents the data, may be seen in figure 3 . Here the deviations ( $p$ observed $-p$ calculated) in $\mathrm{mm}$ $\mathrm{Hg}$ are plotted versus $T$, the calculated values being found by interpolation in table 2 . $\mathrm{Nu}$ merical values of the plotted data are given in table 1 . In figure 3 , points belonging to the same run have been joined by straight lines where this could be done without impairing the clarity of the figure.

The procedure used in preparing table 2 was as follows: For each observed point, $T \log p$ was computed and plotted versus $T$. Over limited ranges $\left(\sim 20^{\circ}\right.$ to $\left.30^{\circ}\right)$ the curves obtained were very nearly straight lines. Accordingly five linear equations of the form $T \log p=A T+B$ were derived and the deviations of the observations from them computed and plotted. Smooth curves were drawn through the points. From these, values were read off at $1^{\circ}$ intervals and added to the corresponding values of the equations. The range covered by each equation overlapped the range of the next higher equation. In the region of overlap both equations were used, and the results adjusted if necessary to join smoothly near the middle of the range. This procedure led to a table of values of $T \log P$ at $1^{\circ}$ intervals. This table was smoothed with a 7-point smoothing formula applied by an Underwood-Sundstrand automatic accounting machine. Deviations of the observations from the smoothed table were plotted, after which the table was adjusted and resmoothed where the data required it. Next, table 2 was computed from the table of $T \log p$. As a final check the deviations of the observations from table 2 were computed and plotted. These are given in table 1 and figure 3 . Table 3 contains values of the vapor pressure at $5^{\circ}$ temperature intervals. It is more convenient than table 2 when rough values are adequate, but table 2 should be used whenever accurate values are to be found by interpolation. 
TABLE 2. Vapor pressure of liquid oxygen

Interpolation with $1 / T$ (or $2 / T$ ) as argument is more accurate and also more convenient than with $T$ as argument. Linear interpolation introduces no significant errors below about $140^{\circ} \mathrm{K}\left(2 / T^{\circ} \mathrm{K}=3.6 / T^{\circ} R=0.0142\right)$. At higher temperatures linear interpolation can introduce slight errors, which however do not exceed $4 \mathrm{~mm} \mathrm{Hg}$ and reach this value only in the immediate neighborhood of the critical point

\begin{tabular}{|c|c|c|c|c|c|c|c|c|c|c|c|c|c|c|}
\hline$\frac{\frac{2}{T}}{{ }^{\circ} K^{-1}}$ & $\frac{{ }^{T} K}{{ }^{\circ}}$ & \multicolumn{4}{|c|}{$\log _{10} p$} & ${ }^{T}$ & $\frac{\frac{3.6}{T}}{{ }^{\circ} R^{-1}}$ & $\frac{\frac{1}{T}}{{ }^{\circ} K^{-1}}$ & $\frac{T}{{ }^{\circ} K}$ & \multicolumn{3}{|c|}{$\log _{10} p$} & $\begin{array}{c}T \\
{ }^{\circ} R \\
180.000\end{array}$ & $\frac{\frac{1.8}{T}}{{ }^{\circ} R^{-1}}$ \\
\hline $\begin{array}{l}{ }^{\circ} K^{-1} \\
0.037 \\
.036 \\
.035 \\
.034 \\
.033\end{array}$ & $\begin{array}{c}{ }^{\circ} K \\
54.054 \\
55.556 \\
57.143 \\
58.824 \\
60.606\end{array}$ & $\begin{array}{c}m m \mathrm{Hg} \\
\mathrm{a}(0.014) \\
.211 \\
.408 \\
.605 \\
.802\end{array}$ & $\begin{array}{c}\text { atm } \\
(7.133) \\
\text { b7. } 330 \\
7.527 \\
7.724 \\
7.921\end{array}$ & $\begin{array}{c}p s i a \\
(8.300) \\
\text { b8. } 497 \\
8.694 \\
8.891 \\
9.088\end{array}$ & $\begin{array}{l}\Delta \\
197 \\
197 \\
197 \\
197 \\
197\end{array}$ & $\begin{array}{c}{ }^{\circ} R \\
97.297 \\
100.000 \\
102.857 \\
105.882 \\
109.091\end{array}$ & $\begin{array}{r}{ }^{\circ} R-1 \\
0.037 \\
.036 \\
.035 \\
.034 \\
.033\end{array}$ & $\begin{array}{c}{ }^{\circ} K^{-1} \\
0.0100 \\
.0099 \\
.0098 \\
.0097 \\
.0096\end{array}$ & $\begin{array}{c}{ }^{\circ} K \\
100.000 \\
101.010 \\
102.041 \\
103.093 \\
104.167\end{array}$ & $\begin{array}{c}m m \text { Hg } \\
3.27989 \\
3.31630 \\
3.35269 \\
3.38905 \\
3.42539\end{array}$ & $\begin{array}{c}\text { atm } \\
0.39908 \\
.43549 \\
.47188 \\
.50824 \\
.54458\end{array}$ & \begin{tabular}{ll}
\multicolumn{2}{c}{$p$ sia $\Delta$} \\
1. 56627 & 3641 \\
1. 60268 & 3639 \\
1. 63907 & 3636 \\
1. 67543 & 3634 \\
1. 71177 & 3630
\end{tabular} & $\begin{array}{c}{ }^{\circ} R \\
180.000 \\
181.818 \\
183.763 \\
185.567 \\
187.500\end{array}$ & $\begin{array}{r}{ }^{\circ} R-1 \\
0.0100 \\
.0099 \\
.0098 \\
.0097 \\
.0096\end{array}$ \\
\hline $\begin{array}{l}.032 \\
.031 \\
.030 \\
.029 \\
.028\end{array}$ & $\begin{array}{l}62.500 \\
64.516 \\
66.667 \\
68.966 \\
71.429\end{array}$ & $\begin{array}{l}.999 \\
1.196 \\
1.392 \\
1.587 \\
1.781\end{array}$ & $\begin{array}{l}8.118 \\
8.315 \\
8.511 \\
8.706 \\
8.900\end{array}$ & $\begin{array}{l}9.285 \\
9.482 \\
9.678 \\
9.873 \\
0.067\end{array}$ & $\begin{array}{l}197 \\
196 \\
195 \\
194\end{array}$ & $\begin{array}{l}112.500 \\
116.129 \\
120.000 \\
124.138 \\
128.571\end{array}$ & $\begin{array}{l}.032 \\
.031 \\
.030 \\
.029 \\
.028\end{array}$ & $\begin{array}{l}.0095 \\
.0094 \\
.0093 \\
.0092 \\
.0091\end{array}$ & $\begin{array}{l}105.263 \\
106.383 \\
107.527 \\
108.696 \\
109.890\end{array}$ & $\begin{array}{l}3.46169 \\
3.49796 \\
3.53419 \\
3.57041 \\
3.60661\end{array}$ & $\begin{array}{l}.58088 \\
.61715 \\
.65338 \\
.68960 \\
.72580\end{array}$ & 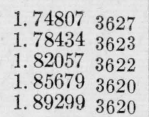 & $\begin{array}{l}189.474 \\
191.489 \\
193.54 \succ \\
195.652 \\
197.802\end{array}$ & $\begin{array}{l}.0095 \\
.0094 \\
.0093 \\
.0092 \\
.0091\end{array}$ \\
\hline$\frac{1}{T}$ & & & & & & & $\frac{1.8}{T}$ & $\begin{array}{l}.0090 \\
.0089 \\
.0088 \\
.0087 \\
.0086\end{array}$ & $\begin{array}{l}111.111 \\
112.360 \\
113.636 \\
114.943 \\
116.279\end{array}$ & $\begin{array}{l}3.642 \curlyvee 1 \\
3.67900 \\
3.71518 \\
3.75137 \\
3.78756\end{array}$ & $\begin{array}{l}.76200 \\
.79819 \\
.83437 \\
.87056 \\
.90675\end{array}$ & 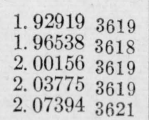 & $\begin{array}{l}200.000 \\
202.247 \\
204.545 \\
206.896 \\
209.302\end{array}$ & $\begin{array}{l}.0040 \\
.0089 \\
.0088 \\
.0087 \\
.0086\end{array}$ \\
\hline 0.0140 & 71.429 & 1. 7807 & 8. 8999 & 0.0671 & 385 & 128.571 & 0.0140 & & & & & & & \\
\hline .0139 & 71.942 & 1. 8192 & 8. 9384 & .1056 & 384 & $12 y .496$ & .0139 & .0085 & 117. 647 & 3. 82377 & .94296 & 2. 110153622 & 211.765 & .0085 \\
\hline .0138 & 72.464 & 1. 8576 & 8.9768 & .1440 & 383 & 130.435 & .0138 & .0084 & 119.048 & 3. 85999 & .97918 & 2. 146373624 & 214. 286 & .0084 \\
\hline .0137 & $\begin{array}{l}72.943 \\
73.529\end{array}$ & $\begin{array}{l}\text { 1. } 8959 \\
\text { 1. } 9342\end{array}$ & $\begin{array}{l}9.0151 \\
9.0534\end{array}$ & $\begin{array}{l}.1823 \\
.2206\end{array}$ & $\begin{array}{l}383 \\
382\end{array}$ & $\begin{array}{l}131.387 \\
132.353\end{array}$ & $\begin{array}{l}.0137 \\
.0136\end{array}$ & $\begin{array}{l}.0083 \\
0082\end{array}$ & $\begin{array}{l}120.482 \\
121.951\end{array}$ & $\begin{array}{l}3.89623 \\
3.93249\end{array}$ & $\begin{array}{l}1.01542 \\
1.05168\end{array}$ & $\begin{array}{l}2.18261 \\
2.21887\end{array}$ & $\begin{array}{l}216.867 \\
219.512\end{array}$ & $\begin{array}{r}0083 \\
0082\end{array}$ \\
\hline & 13.029 & 1. 9542 & 9.0004 & .2200 & 382 & 132.503 & .01000 & .0081 & 123.457 & 3.96880 & 1. 08799 & 2. 2551 ১ 3636 & 222.222 & .0081 \\
\hline $\begin{array}{l}.0135 \\
.0134\end{array}$ & $\begin{array}{l}74.074 \\
74.627\end{array}$ & $\begin{array}{l}\text { 1. } 9724 \\
2.0106\end{array}$ & $\begin{array}{l}9.0916 \\
9.1298\end{array}$ & $\begin{array}{l}.2588 \\
2970\end{array}$ & $\begin{array}{l}382 \\
382\end{array}$ & $\begin{array}{l}133.333 \\
134.328\end{array}$ & $\begin{array}{l}.0135 \\
.0134\end{array}$ & .0080 & 125.000 & 4.00516 & 1. 12435 & 2. $29154 \quad 3640$ & 225.000 & 0080 \\
\hline .0133 & 75. 188 & 2. 0488 & 9. 1680 & .3352 & $\begin{array}{l}382 \\
381\end{array}$ & 135. 338 & .0133 & 0079 & 126.582 & 4. 04156 & 1. 16075 & 2. 327943646 & 227.848 & 0079 \\
\hline .0132 & 75. 758 & 2. $086 y$ & 9.2061 & .3733 & 381 & 136. 364 & .0132 & .0078 & 128.205 & 4. 07802 & 1. 19721 & 2.36440 & 230.769 & .0078 \\
\hline .0131 & 76.336 & 2. 1250 & 9.2442 & .4114 & 381 & 137.404 & .0131 & & & & & & & \\
\hline .0130 & 76. 923 & 2. 1631 & 9. 2823 & .4495 & 381 & 138.462 & .0130 & & & & & & & \\
\hline .0129 & $\begin{array}{l}77.519 \\
78.125\end{array}$ & 2. 2012 & 9. 3204 & .4876 & 380 & 139.535 & $.012 y$ & & + & & & & & \\
\hline $\begin{array}{l}.0128 \\
.0127\end{array}$ & $\begin{array}{l}78.125 \\
78.740\end{array}$ & $\begin{array}{l}\text { 2. } 2392 \\
\text { 2. } 2772\end{array}$ & $\begin{array}{l}9.3584 \\
9.3964\end{array}$ & $\begin{array}{l}.5256 \\
.5636\end{array}$ & $\begin{array}{l}380 \\
378\end{array}$ & $\begin{array}{l}140.625 \\
141.732\end{array}$ & $\begin{array}{l}.0128 \\
.0127\end{array}$ & 2 & & & & & & 3.6 \\
\hline .0126 & 79.365 & 2. 3150 & 9. 4342 & .6014 & 377 & 142.857 & .0126 & $\vec{T}$ & & & & & & $\bar{T}$ \\
\hline .0125 & 80.000 & 2. 3527 & 9. 4719 & .6391 & 377 & 144.000 & .0125 & 0.0156 & 128. 2051 & 4. 07802 & 1. 19721 & 2. $36440 \quad 1826$ & 230. 769 & 0. 0156 \\
\hline .0124 & 80.645 & 2. 3904 & 5096 & .6768 & 376 & 145.161 & .0124 & .0155 & 129.0323 & 4. 09628 & 1. 21547 & 2. $38266 \quad 1826$ & 232. 258 & .0155 \\
\hline .0123 & 81.301 & 2. 4280 & 9. 5472 & .7144 & 376 & 146. 341 & .0123 & .0154 & 129. 8701 & 4. 11454 & 1. 23373 & 2. $400 y 2 \quad 1829$ & 233.766 & .0154 \\
\hline .0122 & 81. 967 & 2. 4656 & 9. 5848 & .7520 & 375 & 147.541 & .0122 & .0153 & 130. 7190 & 4. 13283 & 1. 25202 & 2. $41921 \quad 1832$ & 235.294 & .0153 \\
\hline .0121 & 82.645 & 2. 5031 & 9. 6223 & .7895 & 375 & 148.760 & .0121 & .0152 & 131. 5789 & 4. 15115 & 1. 27034 & 2. 437531834 & 236.842 & .0152 \\
\hline .0120 & 83.333 & 2. 5406 & 9.6598 & .8270 & 375 & 150.000 & .0120 & .0151 & 132.4503 & 4. 16949 & 1. 28868 & 2. $45587 \quad 1836$ & 238.410 & .0151 \\
\hline .0119 & 1. 034 & 2. 5781 & 6973 & .8645 & 375 & 151. 260 & .011 & .0150 & & 4. 1878 & 1. 30704 & 2. $47423 \quad 1840$ & 240.000 & .0150 \\
\hline .0118 & 84.746 & 2. 6156 & 9.7348 & .9020 & 374 & 152.542 & .0118 & .0149 & 134. 2282 & 4. 20625 & 1. 32544 & 2. 492631842 & 241. 611 & .0149 \\
\hline .0117 & 85.470 & 2. 6530 & ч. 7722 & .9394 & 374 & 153.846 & 0117 & .0148 & 135. 1351 & 4. 22467 & 1. 34386 & 2. $51105 \quad 1846$ & 243. 243 & .0148 \\
\hline .0116 & 86.207 & 2. 6904 & ч. 8096 & .9768 & 373 & 155.172 & .0116 & .0147 & 136. 0544 & 4. 24313 & 1. 36232 & 2. $52951 \quad 1849$ & 244.898 & .0147 \\
\hline .0115 & 86.957 & 2. 7277 & 9. 8469 & 1. 0141 & & 156.522 & .0115 & .0146 & 136. 9863 & 4. 26162 & 1. 38081 & 2. $54800 \quad 1853$ & 575 & .0146 \\
\hline & & & & & & & & $\begin{array}{l}.0145 \\
.0144\end{array}$ & $\begin{array}{l}137.9310 \\
138.8889\end{array}$ & $\begin{array}{l}\text { 4. } 28015 \\
\text { 4. } 29871\end{array}$ & $\begin{array}{l}\text { 1. } 39934 \\
1.41790\end{array}$ & $\begin{array}{l}2.56653 \\
2.5850 y\end{array}$ & $\begin{array}{l}248.276 \\
250.000\end{array}$ & $\begin{array}{l}.0145 \\
.0144\end{array}$ \\
\hline .0115 & 86.957 & 2. 72767 & 9.84686 & 1. 01405 & 3725 & 156.522 & .0115 & .0143 & & 4. 31731 & 1. 43650 & 2. 603691864 & 251.748 & .0143 \\
\hline & 719 & 2. 76492 & 9.88411 & 1. 05130 & 3718 & 157.895 & .0114 & .0142 & 140.8451 & 4. 33595 & 1. 45514 & 2. 622331869 & 253.521 & .0142 \\
\hline & 88.496 & 2. 80210 & 9. 92129 & 1. 08848 & 3712 & 159. 292 & .0113 & & & & & & & \\
\hline .0112 & 89.286 & 2. 83922 & 9. 95841 & 1. 12560 & 3704 & 160.714 & .0112 & .0141 & 141.8440 & 4. 35464 & 1. 47383 & 2. $64102 \quad 1875$ & 255. 319 & .0141 \\
\hline .0111 & 90.090 & 2. 87626 & 9.99545 & 1. 16264 & 3697 & 162.162 & .0111 & .0140 & 142.8571 & 4. 37339 & 1. 49258 & 2. 659771880 & 257.143 & .0140 \\
\hline & & & & & & & & .0139 & 143.8849 & 4. 39219 & 1. 51138 & 2. $67857 \quad 1886$ & 258.993 & .0139 \\
\hline .0110 & 90.909 & 2. & 3242 & 19961 & 3690 & 16 & .0110 & .0138 & 144. 9275 & 4. 41105 & 1. 53024 & 2. $69743 \quad 1893$ & 260.870 & .0138 \\
\hline & 91.743 & 2. 95013 & 06932 & 1. 23651 & 3685 & 5. 138 & .0109 & .0137 & 145.9854 & 4. 42998 & 1. 54917 & 2. $71636 \quad 1900$ & 262.774 & .0137 \\
\hline .0108 & 92.593 & 2. 98698 & 10617 & 1. 27336 & 3679 & 166. 667 & .0108 & & & & & & & \\
\hline & 93.458 & 3. 02377 & 0.14296 & 1. 31015 & 3674 & 168. 224 & .0107 & .0136 & 147. 0588 & 4. 44898 & 1. 56817 & 2.73536 1909 & 264.706 & .0136 \\
\hline .0106 & 94.340 & 3. 06051 & 0.17970 & 1. 34689 & 3669 & 169.811 & .0106 & .0135 & 148. 1481 & 4. 46807 & 1. 58726 & 2. $75445 \quad 1919$ & 266. 667 & .0135 \\
\hline & & & & & & & & .0134 & & & 1. 60645 & 2. 773641930 & 268.657 & .0134 \\
\hline .0105 & 95. 238 & 3. 09720 & 0.21639 & 1. 38358 & 3663 & 171.428 & .0105 & .0133 & & 4. 50656 & 1. 62575 & 2. 792941942 & 270.677 & .0133 \\
\hline & 96.154 & & 25302 & 1. 42021 & 3659 & 173.077 & .0104 & .0132 & 151.5152 & 4. $5259 \mathrm{~b}$ & 1.64517 & 2. $81236 \quad 1956$ & 272.727 & .0132 \\
\hline .0103 & 97.087 & 3. 17042 & 0.28961 & 1. 45680 & 3654 & 174.757 & .0103 & & & & & & & \\
\hline & 98.039 & 3. 20696 & 0.32615 & 1. 49334 & 3649 & 176.470 & .0102 & .0131 & 152. 6718 & 4. 54554 & 1. 66473 & 2. $83192 \quad 1977$ & 274.809 & .0131 \\
\hline .0101 & 9у. 010 & 3. 24345 & 0.36264 & 1. 52983 & 3644 & 178.218 & .0101 & .0130 & 153. 8462 & 4. 56531 & 1. 68450 & 2. 851692008 & 276.923 & .0130 \\
\hline .0100 & 100.000 & 3. 27989 & 0.39908 & 1. 56627 & & 180.000 & .0100 & .0128 & 156.2500 & (4. 60589) & (1. 72508$)$ & $(2.89227)^{2050}$ & 281. 250 & .0128 \\
\hline
\end{tabular}

a Parentheses inỏicate extrapolated values, outside normal liquid range.

b Logarit hms nave been increased by 10 wherever necessary to avoid negative mantissas. 

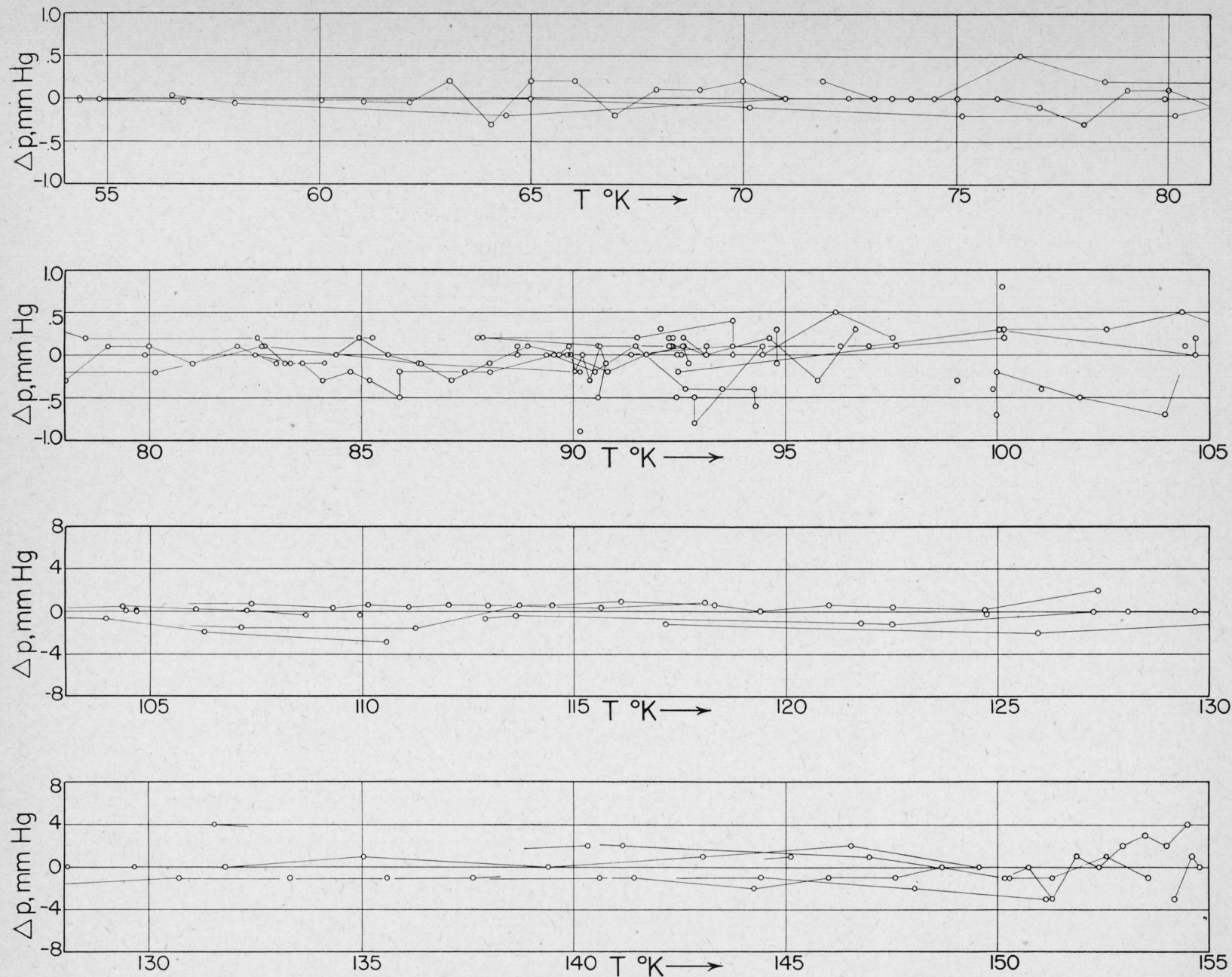

FIGURE 3. Deviations (observed-calculated) of the observed vapor-pressure data from table 2.

TABLE 3. Vapor pressure of oxygen at uniform temperature intervals; also triple-point, boiling-point, and critical-point temperatures and pressures

\begin{tabular}{|c|c|c|c|c|c|c|c|}
\hline$T$ & $p$ & $p$ & $p$ & $T$ & $p$ & $p$ & $p$ \\
\hline${ }^{\circ} K$ & $m m \mathrm{Hg}$ & atm & psia & ${ }^{\circ} K$ & $m m \mathrm{Hg}$ & atm & psia \\
\hline${ }^{t} 54.363$ & 1.14 & 0.00150 & 0.022 & 95 & 1223.3 & 1. 6096 & 23.65 \\
\hline b 90.190 & 760.0 & 1. & 14.696 & 100 & 1905. 0 & 2. 5066 & 36.84 \\
\hline \multirow[t]{2}{*}{ c 154.780} & 38,109 & 50.14 & 736.9 & 105 & 2838.2 & 3. 7345 & 54.88 \\
\hline & & & & 110 & 4072.9 & 5. 3591 & 78.76 \\
\hline 55 & 1. 38 & 0.00182 & 0.027 & 115 & 5661.6 & 7. 4495 & 109.48 \\
\hline 60 & 5. 44 & .00716 & .105 & 120 & 7658.6 & 10.077 & 148.09 \\
\hline 65 & 17.4 & .0229 & .34 & 125 & 10,120 & 13.316 & 195.7 \\
\hline 70 & 46.8 & .0616 & .90 & 130 & 13,102 & 17. 239 & 253.4 \\
\hline 75 & 108.7 & .1430 & 2.10 & 135 & 16,670 & 21. 934 & 322.3 \\
\hline 80 & 225.3 & .2964 & 4. 36 & 140 & 20,892 & 27. 489 & 404.0 \\
\hline 85 & 425.4 & .5597 & 8. 23 & 145 & 25,843 & 34.004 & 499.7 \\
\hline 90 & 745.0 & .9803 & 14.41 & 150 & 31,631 & 41.620 & 611.6 \\
\hline
\end{tabular}

$\mathrm{t}$ Triple point.

b Boiling point.

- Critical point. 
Accuracy of the results. The average deviation from table 2 of the points measured with the oil manometer is $0.014 \mathrm{~mm} \mathrm{Hg}$. Where the mercury manometer was used alone, the average deviation was $0.13 \mathrm{~mm} \mathrm{Hg}$. Where mercury manometer and barometer were both read, the corresponding figure was $0.22 \mathrm{~mm} \mathrm{Hg}$. For piston gage readings where the diaphragm cell was employed, the average deviation was $0.84 \mathrm{~mm} \mathrm{Hg}$, and where the pressure transmitter shown in figure 1 was used the deviation was $1.13 \mathrm{~mm} \mathrm{Hg}$.

The first two runs (March 16 and 17, 1942) were made under rather unfavorable conditions. At that time the tube heater was so controlled that the tube thermel indicated a temperature equal to that of the calorimeter. Later it was found that a somewhat higher temperature was required to avoid all danger of a cold spot on the tube. The values are probably correct, at least within the limits of their agreement with the later data. They are included because of the scarcity of data at the lowest pressures. They contain the three measurements made on solid oxygen. As mentioned earlier, leakage of helium from the resistance thermometer caused trouble at one stage in the measurements. This was eliminated by operating with a small amount of helium in the space inside the shield. All data subject to error from loss of helium from the thermometer were discarded.

Three possible sources of error must be considered: impurity in the material; the pressure measurements; and the temperature measurements. Effect of impurity is believed to be small compared to other errors. Between the triple point and $95^{\circ} \mathrm{K}$, which is about the upper limit of the $\mathrm{HgB}$ measurements, pressures are thought to be accurate to 0.1 or $0.2 \mathrm{~mm} \mathrm{Hg}$. This refers to the smoothed values given by table 2 rather than to individual measurements. Above the range of mercury manometry the uncertainty increases to 1 or $2 \mathrm{~mm} \mathrm{Hg}$, and then gradually increases still more as the pressure rises. The uncertainty near the critical point may be $10 \mathrm{~mm}$ $\mathrm{Hg}$, which is about 1 part in 4,000. Each of the last three values in table 1 is an average obtained from the isotherm data of table 5, and hence is somewhat more accurate than other values in the neighborhood.

Errors associated with temperature measurements are more difficult to estimate. The re- producibility of temperature measurements with a given thermometer was easily $1 / 2$ mdeg. The triple-point determinations made with thermometers L3 and L14 agreed to better than 1 mdeg, which indicates that the accuracy of our calibrations on the PTS is of the order of 1 or 2 mdeg. It is hoped that the PTS does not deviate from the thermodynamic scale by more than $20 \mathrm{mdeg}$ [1]. Above the oxygen boiling point the ITS was used. The reproducibility of this scale depends on the distances to the nearest calibration points, which in this case were $90.19^{\circ}$ and $273.16^{\circ} \mathrm{K}$. At the critical point $\left(154.78^{\circ} \mathrm{K}\right)$ the uncertainty in the ITS may be as large as 5 mdeg. This does not include any allowance for deviations of the ITS from the thermodynamic scale, which may be as large as 50 mdeg. A few comparisons of temperature scales are made later in this paper.

Comparison with previous work. The more important previous investigations of the vapor pressure of liquid $\mathrm{O}_{2}$ are listed in table 4. This table gives the range covered by each set of observations and the number of experimental points. A number of isolated values of the vapor pressure of oxygen have been reported, most of them in the neighborhood of the boiling point. These have been omitted from table 4 , as have some of the earlier investigations covering more extended ranges. Stull's [21] references give a very complete coverage of both the older and the more recent work on the vapor pressure of oxygen. Additional references are also given in reference [22].

TABLE 4. Some previous investigations of the vapor pressure of liquid oxygen

Some additional data, which cover only the neighborhood of the normal boiling point, are referred to in table 6

\begin{tabular}{|c|c|c|c|}
\hline Year & Reference & Range covered & $\begin{array}{l}\text { Num- } \\
\text { ber of } \\
\text { obser- } \\
\text { vations }\end{array}$ \\
\hline 1913 & Siemens [14] & 2.68 to $766.8 \mathrm{~mm} \mathrm{Hg} \ldots$ & 10 \\
\hline 1914 & $\begin{array}{l}\text { Onnes, Dorsman, and } \\
\text { Holst [4]. }\end{array}$ & 9.096 to $23.59 \mathrm{~atm}$ & 13 \\
\hline 1918 & Cath $[15] \ldots$ & 0.01262 to $1.0350 \mathrm{~atm}$ & 10 \\
\hline 1924 & Henning and Heuse [16] ... & 35.1 to $773.2 \mathrm{~mm} \mathrm{Hg}$ & 26 \\
\hline 1927 & $\begin{array}{l}\text { Giauque, Johnston, and } \\
\text { Kelley [17]. }\end{array}$ & 60.46 to $757.15 \mathrm{~mm} \mathrm{Hg}$ & 5 \\
\hline 1927 & $\begin{array}{l}\text { Dodge and Davis (also } \\
\text { Dumbar) [3]. }\end{array}$ & 0.208 to $21.47 \mathrm{~atm}$ & 64 \\
\hline 1935 & Aoyama and Kanda [18] ... & 2.04 to $17.85 \mathrm{~mm} \mathrm{Hg}$ & 3 \\
\hline 1935 & $\begin{array}{l}\text { Aston, Willihnganz, and } \\
\text { Messerly [19]. }\end{array}$ & 11.28 to $746.70 \mathrm{~mm} \mathrm{Hg}$ & 8 \\
\hline 1936 & Henning and Otto [20] $\ldots$ & 25.17 to $739.90 \mathrm{~mm} \mathrm{Hg}$... & 19 \\
\hline
\end{tabular}



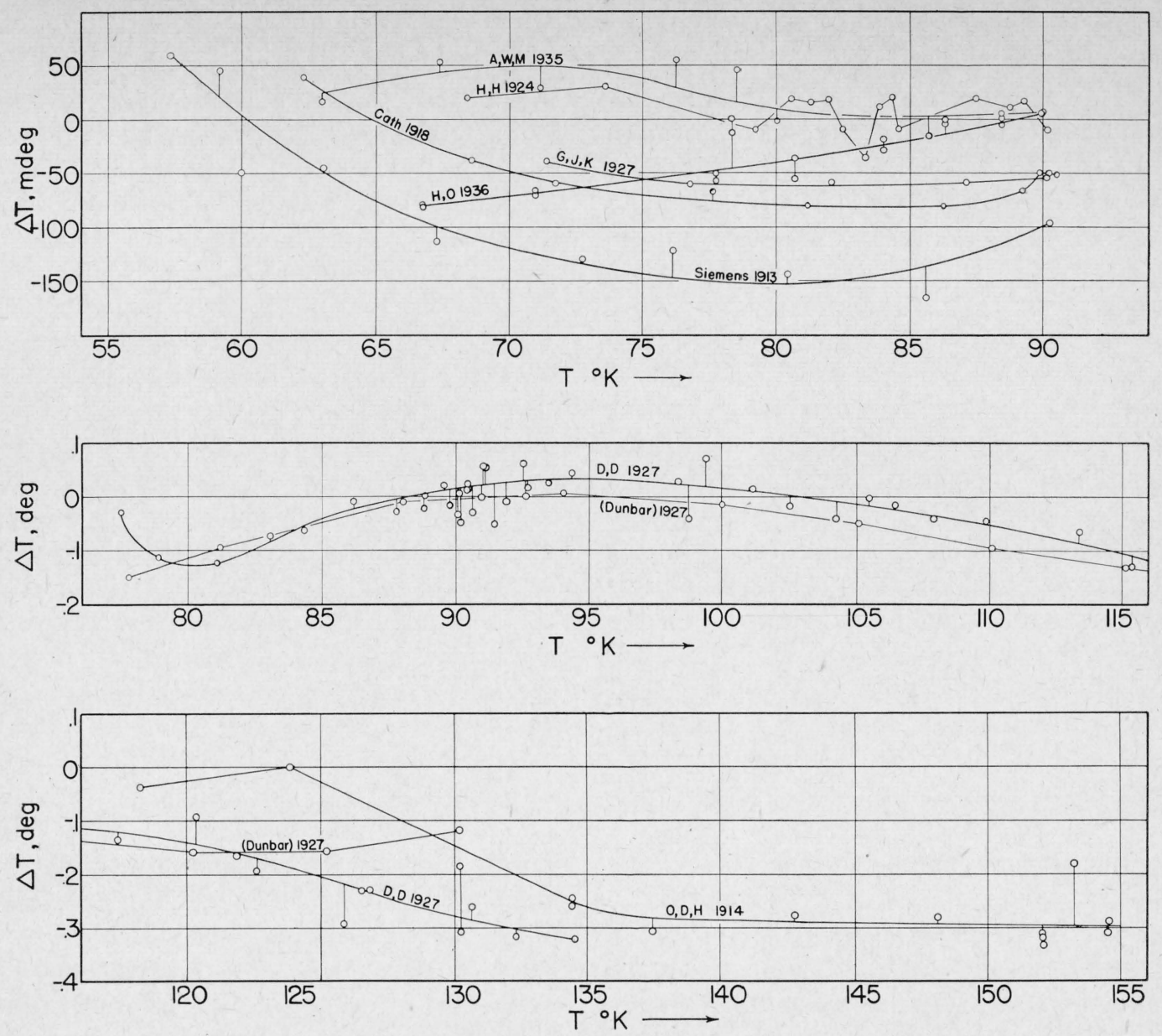

FIgURE 4. Comparison of the vapor-pressure data of various observers.

The ordinate is the temperature reported by the observer minus the temperature calculated from table 2 .

For all of the data referred to in table 4, deviations from table 2 were computed. These are plotted in figure 4 , with the exception of the three points in the paper of Aoyama and Kanda [18]. These had negative deviations of more than half a degree and so are beyond the range of the graph. It is the writer's belief that figure 4 is more instructive as a comparison of various temperature scales than as a comparison of accuracy in pressure measurement, and for this reason the deviations in Figure 4 are in terms of temperature rather than in terms of pressure as in figure 3 . The data of Aoyama and Kanda just referred to are probably in error because of unsatisfactory pressure measurements, and this may be true of the data of Onnes, et al.; but most of the differences between the rest of the data and table 2 are probably associated with the temperature. The temperatures of Henning and Heuse [16] were converted from the centigrade to the Kelvin scale with $T_{0}=273.20$.

In the range below $90^{\circ} \mathrm{K}$ the negative deviations considerably outweigh the positive ones. If however the older data of Siemens [14] and Cath [15] are excluded, there is not a great preponderance of deviations of either sign. Above $90^{\circ} \mathrm{K}$ the data plotted are those of Dodge and Davis [3] (including those of Dodge and Dunbar in the same reference) and those of Onnes, Dorsman, and Holst [4]. The former show good agreement with table 2 at $90^{\circ}$ but fall more and more below it at higher temperatures, reaching an extreme of about $-0.3^{\circ}$ at $134^{\circ} \mathrm{K}$. Dodge and Davis calibrated their thermocouple at the boiling points of $\mathrm{N}_{2}, \mathrm{O}_{2}$, and $\mathrm{CH}_{4}$ using for the temperature of the last $111.52^{\circ} \mathrm{K}$. A currently accepted [23] value for the boiling point of $\mathrm{CH}_{4}$ is $111.67^{\circ} \mathrm{K}$, which is 0.15 higher. Dodge and Davis obtained 
temperatures above this point by extrapolating their calibration, which could easily have introduced the remainder of the $-0.3^{\circ}$ discrepancy. The two lowest points of Onnes et al. agree fairly well with table 2 . The higher points are nearly all about $0.3^{\circ}$ below it. It may be significant that the first two points were measured with a multiple-column mercury manometer and the rest with a closed-end hydrogen-filled manometer.

\section{Isotherms}

Measurements of isotherms ( $p$ versus $v$ ) were made to determine the critical temperature and pressure and also vapor pressures immediately below the critical point. The measurement of an isotherm was similar to a series of vapor-pressure measurements all at the same temperature, except that after each measurement the amount of water in the pressure-transmitting line (see fig. 1) was changed. This varied the height $h_{1}$ of the first meniscus and caused $\mathrm{O}_{2}$ to flow out of the cryostat into the transmitting line or vice versa. Change in $h_{1}$ made it necessary of course to rebalance the piston gage even when the change in $h_{1}$ did not change the pressure in the equilibrium chamber. Table 5 contains the results of the isotherm measurements, after adjustment of each series to a common temperature. The adjustments were made in $\log p$, using values of $d \log$

\section{TABLE 5. Isotherm data}

Mean specific volume, $v$, of material in equilibrium chamber was varied by changing the height of the mercury column in contact with $0_{2}$ vapor

\begin{tabular}{|c|c|c|c|}
\hline Date & $T$ & $v$ & $p$ \\
\hline $\begin{array}{l}\text { Dec. } 21 \text { and } 29,1948 \ldots \\
\text { Dec. } 23,1948 \ldots\end{array}$ & $\begin{array}{r}{ }^{\circ} K \\
154.187_{5} \ldots \\
154.580_{3} \ldots \\
\end{array}$ & $\begin{array}{r}\mathrm{cm}^{3} g^{-1} \\
2.72 \\
3.02 \\
2.33 \\
2.57 \\
2.73 \\
2.93 \\
3.22 \\
\\
1.97 \\
2.07 \\
2.18 \\
2.31 \\
2.44 \\
2.59 \\
2.77 \\
2.97 \\
3.21 \\
3.49 \\
2.78 \\
\\
2.79 \\
2.88 \\
3.06 \\
2.72 \\
2.58 \\
2.46 \\
2.32 \\
2.64\end{array}$ & $\begin{array}{l}m m \mathrm{Hg} \\
37,239 \\
37,239 \\
37,247 \\
37,241 \\
37,239 \\
37,237 \\
37,233 \\
38,586 \\
38,114 \\
37,895 \\
37,829 \\
37,817 \\
37,816 \\
37,814 \\
37,804 \\
37,742 \\
37,592 \\
37,818 \\
38,060 \\
38,047 \\
38,006 \\
38,071 \\
38,078 \\
38,090 \\
38,115 \\
38,078\end{array}$ \\
\hline
\end{tabular}

$p / d T$ derived from table 2 . The largest adjustment was less than 4 mdeg.

Knowing $h_{1}$ it was possible to compute the specific volume $v$ of the $\mathrm{O}_{2}$ remaining in the equilibrium chamber. Some of the data entering into this calculation were not well known, and so the values of $v$ are not very accurate, but this has no effect on the observations of pressure and temperature. In figure 5, the isotherm data of table 5 are plotted versus $v$. The three isotherms are all below the critical temperature. The highest $\left(154.760^{\circ} \mathrm{K}\right)$ has a short horizontal portion. ${ }^{5}$

To help in estimating the temperature of the critical isotherm from figure 5 , the shapes of the isotherms in this figure were compared with the accurate isotherms covering the critical region of $\mathrm{CO}_{2}$ published by Michels, Blaisse, and Michels [25]. From the comparison it was estimated that the critical temperature of $\mathrm{O}_{2}$ is $154.78^{\circ} \pm 0.03^{\circ}$ $\mathrm{K}$. This is $0.02^{\circ}$ above the highest isotherm in figure 5. Accepting this value of $T_{c}$, the critical

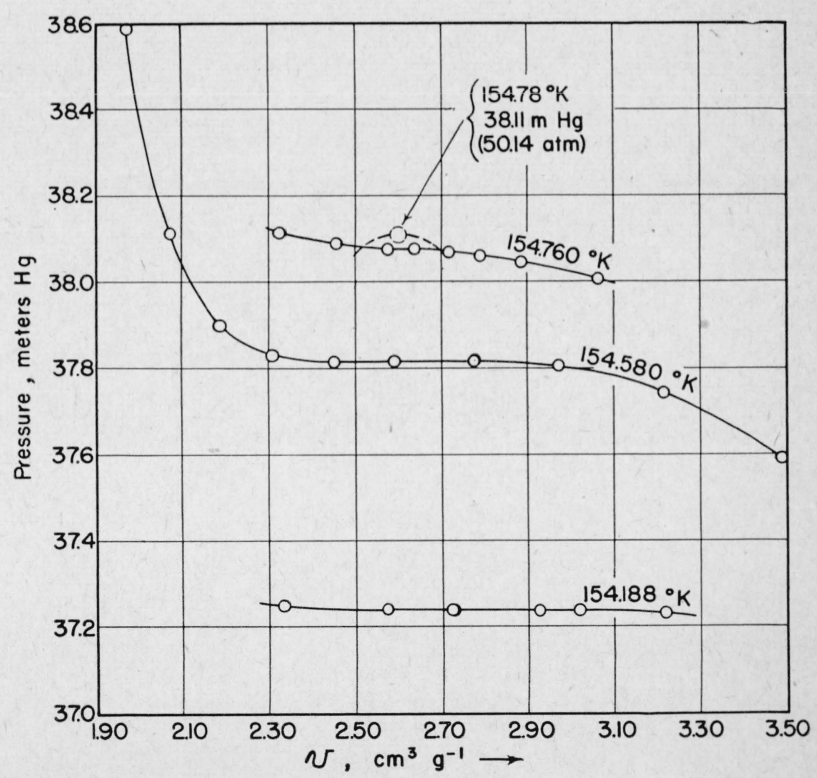

Figure 5. Isotherms of oxygen, showing pressure as a function of specific volume.

The estimated position of the critical point is shown by the dotted circle.

${ }_{5}$ When the correction for hydrostatic pressure of $\mathrm{O}_{2}$ vapor is computed from the middle of the equilibrium chamber as was done in the present case, the critical isotherm will not appear to be exactly flat. The exact critical condition progresses from the bottom of the chamber to the top as the material is compressed, so that the hydrostatic correction should strictly be varied along the length of an isotherm. The equilibrium chamber was about $47 \mathrm{~mm}$ high. A $47-\mathrm{mm}$ column of $\mathrm{O}_{2}$ at the critical density of $0.43 \mathrm{~g} \mathrm{c} \mathrm{m}^{-3}$ [24] exerts a hydrostatic pressure of about $1.5 \mathrm{~mm} \mathrm{Hg}$. Hence an isotherm that was in truth flat should show a variation of this amount when computed and plotted as in figure 5 . 
pressure is found from table 2 to be $p_{c}=38,109 \pm 50$ $\mathrm{mm} \mathrm{Hg}$ (50.14 atm).

The method by which $v$ was computed from $h_{1}$ will be briefly explained. It was necessary to know the mass of $0_{2}$ in the equilibrium chamber and the connecting tubes extending to the valve $V_{1}$ and the mercury surface $h_{1}$. It was also necessary to know the volumes and temperatures of the various parts of this volume. This permitted the mass of $\mathrm{O}_{2}$ outside the equilibrium chamber to be computed from the known properties of oxygen gas. The mass of $0_{2}$ in the equilibrium chamber could then be determined by difference. Division of the volume of the equilibrium chamber by this mass gives $v$. That is, $v$ is the mean specific volume for the entire chamber, without regard for the fact that two phases were sometimes present.

The volume $V$ containing the known mass of $0_{2}$ can be expressed as $V=V_{0}-a h_{1}$, where $a$ is the known inside cross section of the pressure transmitter $\left(0.96_{8} \quad \mathrm{~cm}^{2}\right)$. The volume $V$ was known approximately from the dimensions of the apparatus, but was measured accurately as follows: With all parts of $V$ near room temperature, gas was admitted to a pressure of about 1 atm, which pressure was measured by the height $h_{2}-h_{1}$. The space above $h_{2}$ (later filled with water) had been previously evacuated. Next the space above $h_{2}$ was opened to the atmosphere, and after time for thermal equilibrium the new pressure in $V\left(=h_{2}-h_{1}+\right.$ barometer $)$ was observed. Two or more pairs of values of $p$ and $h_{1}$ plus the ideal gas law permit $V$ to be determined as a function of $h_{1}$. If necessary $V$ may be treated as a sum of subvolumes each at a different temperature. Several measurements of the type just described gave the following equation, which was accepted for $V$

$$
V\left(\mathrm{~cm}^{3}\right)=84.45-0.0968 h_{1}(\mathrm{~mm}) .
$$

When this value was checked by computing $V$ from the dimensions of the apparatus, a value $1.15 \mathrm{~cm}^{3}$ smaller was found. For this reason the specific volumes given in table 5 and figure 5 are rather uncertain.

Computed volumes of various parts of $V$ were adjusted to give agreement with the observed total volume (eq 1). Then from the known pressure, the mass of $\mathrm{O}_{2}$ at room temperature (assumed to be $300^{\circ} \mathbf{K}$ ) was computed, using compressibility factors from reference [26]. The temperature change from equilibrium chamber to room temperature occurred in a vertical section of tube. Hence the mass of $\mathrm{O}_{2}$ in this tube could be readily obtained from the integral computed for the hydrostatic pressure corrections to the vapor pressure measurements.

The total mass of $\mathrm{O}_{2}$ in $V$ was obtained by noting the fall of pressure in the calibrated volume and connecting lines when the mass was transferred to the cryostat. The temperatures of the calibrated volume and the connecting lines were observed. The volumes of the connecting lines including the $\mathrm{Hg}$-in-glass manometer were found by means similar to those used in determining $V$.

From figure 5 the critical density of $\mathrm{O}_{2}$ is about $1 / 2.6=0.38 \mathrm{~g} \mathrm{~cm}^{-3}$. By making the most extreme assumptions in distributing the $1.15-\mathrm{cm}^{3}$ discrepancy previously referred to among the various parts of $V$, the computed critical density can be raised from 0.38 to about $0.44 \mathrm{~g} \mathrm{~cm}^{-3}$. Comparison of earlier values of $T_{c}, p_{c}$, and $\rho_{c}$ with those given in this paper is deferred until after presentation of the calorimetric measurements in the critical region.

\section{Heat Capacities in the Critical Region}

Heat-capacity measurements were undertaken to investigate the nature of the changes that take place near the critical point and also to determine whether or not calorimetric methods of determining the critical constants could compete with conventional methods. The apparatus was primarily designed for vapor-pressure work and had several drawbacks as a calorimeter. Hence the results are only indicative of what could be done with a calorimeter properly designed for highpressure work.

Measurements. All of the heat-capacity measurements were made in the PGD (piston gagediaphragm cell) apparatus. A known quantity of $\mathrm{O}_{2}$ was introduced into the volume $V$, which comprised the equilibrium chamber and the lines extending from it to the valve $V_{1}$ and to the diaphragm cell. The quantity of $\mathrm{O}_{2}$ introduced into $V$ was determined from the fall in pressure in the calibrated volume, as in the case of the isotherm measurements. With the diaphragm cell, eq 1 for $V$ does not apply. Except for motion of the 
diaphragm, V remains constant. Direct measurement of $V$ by gas-law methods similar to those described in the section on isotherms again showed $V$ to be more than $1 \mathrm{~cm}^{3}$ larger than the value computed from available dimensions.

With a known mass of $\mathrm{O}_{2}$ in $V$, heat-capacity measurements were made in the usual way by measurement of $E, I$, and the heating time, $t$. The shields were kept at the temperature of the calorimeter at all times. The chief weakness of the apparatus as a calorimeter was the rather short path for heat flow between the copper block (fig. 2) and the shield, along the two pressuretransmitting tubes and the larger supporting tube. Heat leak here might be expected to affect the gross and tare heat capacities about equally, however, The latter were measured with $V$ evacuated. Owing to the small size of the sample of $\mathrm{O}_{2}$ in $V(1.63$ to $4.00 \mathrm{~g})$ the net heat capacity was a rather small fraction of the gross heat capacity ( $\sim 5$ to $10 \%$ except near the maxima).

Because the conditions under which the heat capacity was measured are somewhat unusual, it will be worth while to enumerate the various processes taking place in the calorimetric system as measurements are made. Most of the energy supplied is absorbed by the calorimeter (tare heat capacity). The rest is absorbed by the sample. If the calorimeter contains both liquid and vapor, part of the energy will go to raise the temperature of each phase, and in addition some material will in general pass from one phase to the other, resulting in the absorption or liberation of heat of vaporization. Besides these processes, the rise in temperature increases the vapor pressure of the material. This causes vapor to flow out of the calorimeter into the pressure-transmitting tube where its heat capacity is no longer measured. The measurements yield a quantity that is not very closely related to the familiar $C_{s a t}, C_{v}$, or $C_{p}$ of a single phase, although these heat capacities can be computed from the measurements if certain auxiliary data are known with adequate accuracy.

Although the heat capacities of the individual phases have not in general been computed from the present measurements, the significance of the results is perhaps most easily grasped by giving the relation between them and the heat capacities of the individual phases. The quantity reported is also rather simply related to the slopes of certain lines on the entropy-temperature diagram. In a previous publication the author [27] derived relations between the heat capacity, $c_{c}$, of saturated condensed phase and that of a two-phase system consisting of saturated condensed phase and vapor in equilibrium. Although these were developed primarily to permit correcting for the presence of vapor, they can easily be modified for use in the case under discussion. The present experiments were of type 4 according to the classification of the paper referred to (gross charge, $M$; tare charge, $O$; filling tube, yes). For this type of experiment the net observed heat capacity (gross minus tare) of the two phases in the calorimeter is

$$
C_{n e t}=\left(M-M_{t}\right) c_{c}+T \frac{d S^{\prime}}{d T}+l \frac{d M_{t}}{d T}
$$

where $M_{t}$ is the mass of material in the tube (outside the calorimeter proper), $S^{\prime}$ is the "excess entropy" of the material in the calorimeter proper, and $l$ is the heat of vaporization per gram. The "excess entropy" is the excess above the entropy of the same mass of saturated condensed phase and may be computed either from latent heat or vapor-pressure data when these and certain other auxiliary data are known. The term $l\left(d M_{t} / d T\right)$ is the contribution to the heat capacity of the heat of vaporization of that material which is forced out of the calorimeter by the rising pressure.

In analyzing the present results, the mass $M_{t}$ was computed by the methods outlined in the section on isotherms, using the same values as were used there for the various subvolumes of $V$. The term $l\left(d M_{t} / d T\right)$ was then computed and subtracted from $C_{n e t}$ for all points where two phases were actually present in the calorimeter. Division by $M-M_{t}$, the mass of material present in the calorimeter, and multiplication by $W$, the molecular weight, gave the molar heat capacity under the conditions of the experiment, which is

$$
C\left(j \mathrm{~mole}^{-1}\right)=C_{c}+\frac{W T}{M-M_{t}} \frac{d S^{\prime}}{d T} .
$$

This quantity has been plotted in figure 6. Except in one isolated case mentioned later, the two terms on the right were not separately evaluated. Each of the six curves in the figure was taken with a different mass of material in the calorimeter so that data would be obtained at volumes both above and below the critical. All but the top curve have pronounced maxima corresponding to 


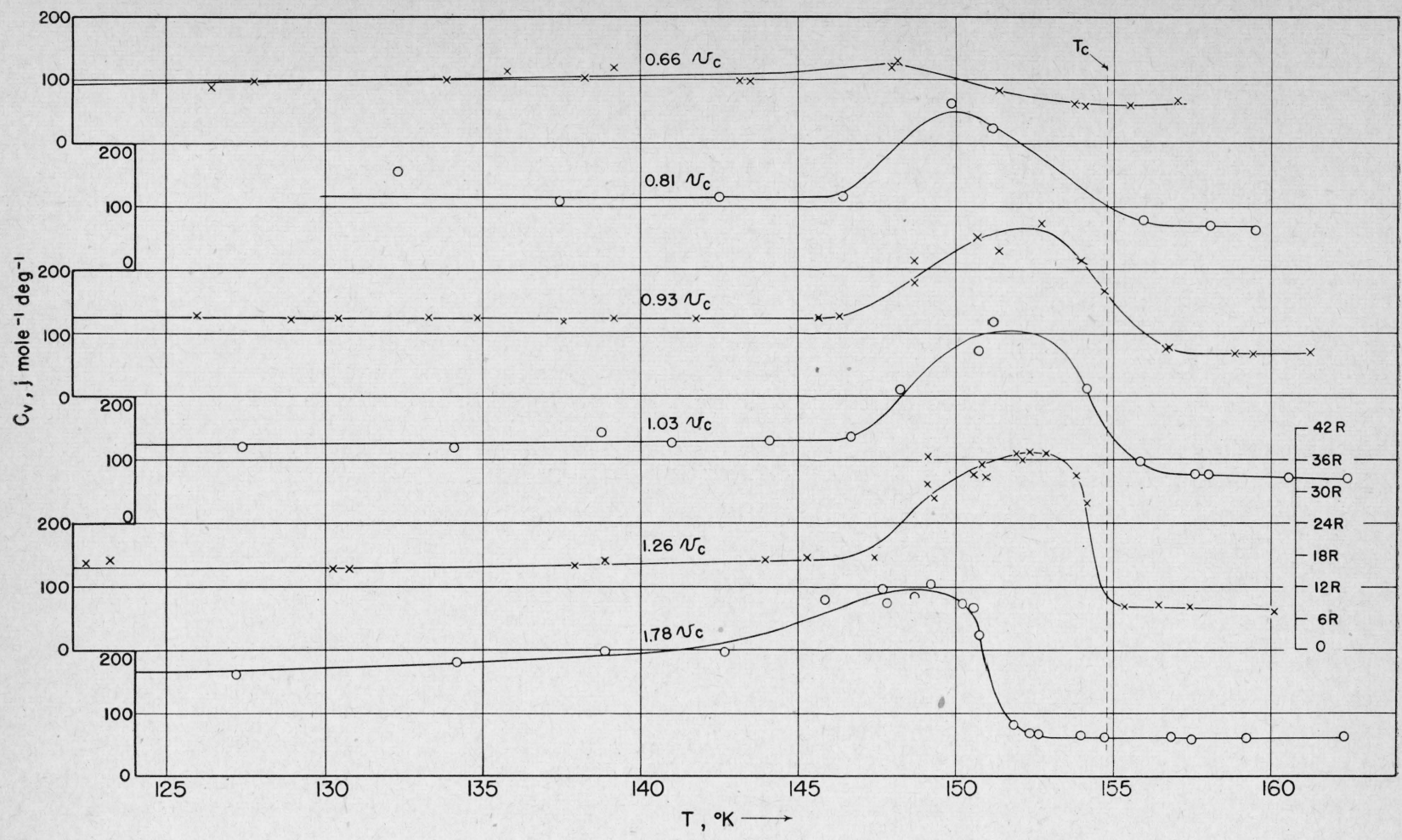

Figure 6. Molar heat capacity, $C_{v}$, of oxygen at various specific volumes.

Maxima in the curves are caused by the rapid absorption of the heat of vaporization.

a much more rapid absorption of heat as the critical temperature is approached. The quantity plotted is a property of the material, but as the figure shows, it also depends on volume. Owing to the gradual increase in $M_{t}$, the curve obtained with any one filling does not correspond to a constant volume line, although it approximates rather closely to such a line at temperatures well below the critical. The mass of material present in the calorimeter falls by 10 or 20 percent as the pressure rises, so the over-all specific volume of the material being measured increases by this amount. The molar volumes given in figure 6 for each curve were computed for the temperatures at which the respective maxima occurred.

On the entropy-temperature diagram the paths followed are at first approximately constantvolume lines in the two-phase region, but as the temperature rises the paths deviate more and more in the direction of higher volumes. Figure 7 is an $S-T$ diagram, drawn somewhat schematically. Along any path in such a diagram, $C_{\text {path }}=T(d S / d T)_{\text {path }}$, because of the fundamental relation $d S=\delta Q / T$. Hence the slope of a constantvolume line is $T / C_{v}$, and the slope of any path is
$T / C_{\text {path }}$. The maxima in the heat-capacity curves of figure 6 correspond therefore to the portions of the paths having the least slopes. Three constantvolume lines (solid curves) are drawn in figure 7 , about as they usually appear in $S-T$ diagrams. These lines have a slowly decreasing slope in the two-phase region, with an abrupt increase in slope at the boundary. This corresponds to a slowly increasing heat capacity while two phases are present, with an abrupt drop to a lower heat capacity on crossing the boundary of the liquidvapor dome.

The two lowest heat-capacity curves of figure $6\left(v=1.78 v_{c}\right.$ and $\left.v=1.26 v_{c}\right)$ show that a rather abrupt drop does occur at the dome boundary when the volume is considerably greater than the critical volume. At the critical and all lower volumes, however, the drop is gradual rather than abrupt, but there is a region of high heat capacity several degrees wide before the dome boundary is crossed. The paths followed on the $S-T$ diagram therefore look more like the two dotted curves than like the solid curves. It would seem that the differences in the two sets of curves are a little too large to be entirely accounted for by the 
gradual increase in molar volume of the material. If this is the case, the constant-volume lines in an $S-T$ diagram should be drawn with short sections of high curvature at the dome boundary rather than sharp breaks, at least for $v$ less than $v_{c}$.

Accurate calorimetric data would permit the construction of an $S-T$ diagram, and those quantities most difficult to determine from $p-I-T$ data would be most easily found by calorimetry. The present data were not considered accurate enough to warrant the construction of such a diagram, but they indicate what might be done with a calorimeter containing a larger sample, with better thermal isolation, and preferably without the complication of a filling tube permanently in communication with the equilibrium chamber. ${ }^{6}$

The curves of figure 6 show that the heat capacity of a sample always drops when the calorimeter is entirely filled with one phase, regardless of whether this phase is liquid or vapor. In the lowest filling $\left(v=1.78 v_{c}\right)$ both liquid and vapor were present up to about $151^{\circ} \mathrm{K}$, at which temperature all the liquid had evaporated. In the highest filling $\left(v=0.66 v_{c}\right)$ the liquid ex-

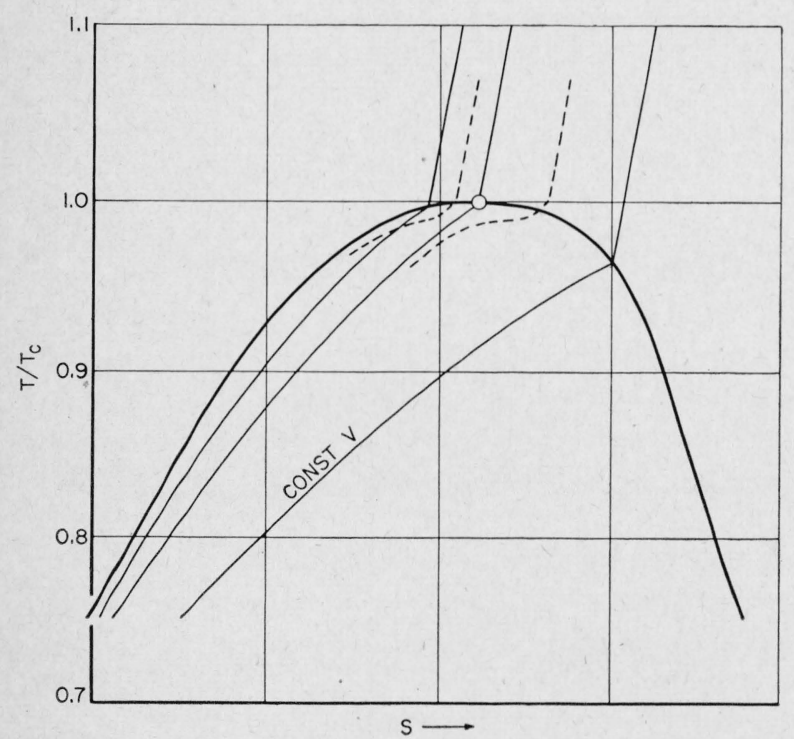

Figure 7. Schematic entropy-temperature diagram.

The heat-capacity curves of figure 6 correspond more closely to the dotted constant-volume lines than to the solid lines with sharp breaks in them.

${ }^{6}$ Professor A. Michels (private communication) states that the Van Der Waals Laboratory will shortly publish measurements of the heat capacity of $\mathrm{CO}_{2}$ extending through the critical region. These give promise of furnishing a more conclusive demonstration of the value of high-pressure calorimetry than the present results. panded until at about $148^{\circ} \mathrm{K}$ it entirely filled the calorimeter.

A few somewhat puzzling facts regarding figure 6 should be pointed out. At temperatures above their respective maxima all the curves drop to values lying between 60 and $70 \mathrm{j} \mathrm{mole}^{-1} \mathrm{deg}^{-1}$. Only one phase is present in the calorimeter and (at least for the three lower curves) material is not being forced out of the calorimeter as rapidly as it was at the maxima. Hence the heat capacity, which must lie somewhere between $C_{v}$ and $C_{p}$, should in fact be rather close to $C_{v}$. For molecular oxygen in this temperature range the heat capacities in the ideal gas state are $C^{\circ}{ }_{p}=29.12$ and $C^{\circ}{ }_{v}=20.81 \mathrm{j} \mathrm{mole}^{-1} \mathrm{deg}^{-1}[28]$. The observed values are therefore about $65-25=40 \mathrm{j} \mathrm{mole} \mathrm{m}^{-1}$ $\mathrm{deg}^{-1}$ or about $5 R$ higher than the ideal gas value. This seems rather high in comparison with similar data for other substances. For example, Bennewitz and Splittgerber [29] measured $C_{v}$ for $\mathrm{CO}_{2}$ through the critical region, at one volume slightly below and another slightly above the critical volume. The two values of $C_{v}$ that they obtained at $40^{\circ} \mathrm{C}$ (about $9 \mathrm{deg}$ above $T_{c}$ ) differ by less than 2 percent, the average being $56.0 \mathrm{j}$ mole $^{-1}$ $\mathrm{deg}^{-1}$. This value is in fairly good agreement with the results of Michels and de Groot [30], who computed heat capacities from $P-V-T$ data. At $40^{\circ} \mathrm{C}$ and approximately the critical volume, the latter give $C_{v}=53.7$. The ideal gas value at $40^{\circ} \mathrm{C}$ is about 29.3 [31], so $C_{v}-C^{\circ}{ }_{v} \doteq 55-29.3=$ $25.7 \mathrm{j} \mathrm{mole}^{-1} \mathrm{deg}^{-1}$, or $3.1 R$. Data are also available for ethylene. Pall, Broughton, and Maass [32] measured $C_{v}$ for ethylene at a volume slightly less than the critical. At $22^{\circ} \mathrm{C}$ (about $12.5 \mathrm{deg}$ above $T_{c}$ ) they found $47.5 \mathrm{j} \mathrm{mole}^{-1} \mathrm{deg}^{-1}$, whereas the ideal gas value [33] is about 34.9 . Hence $C_{v}-C^{\circ}{ }_{v}=12.6$, or $1.5 R$.

The excess of the heat capacity of a fluid above the value in the ideal gas state may be computed from an equation of state. Unfortunately, there does not appear to be any such equation that represents the behavior of oxygen in the critical region. Using the Beattie-Bridgeman equation, with constants that fit the $P-V-T$ data for oxygen at somewhat lower densities, a calculated value of $C_{v}-C_{v}^{\circ}=1.2 R$ is obtained at the critical density and slightly above the critical temperature. A similar calculation for $\mathrm{CO}_{2}$ gave $C_{v}-C_{v}^{\circ}=1.8 R$. W. S. Benedict made calculations using the Kellogg equation in a reduced form that gives a yery good 
representation of the behavior of hydrocarbons, and also using Su and Chang's reduced form of the Beattie-Bridgeman equation. At the critical density and temperature the result with the Kel$\operatorname{logg}$ equation was $C_{v}-C_{v}^{\circ}=1.3 R$, and with the reduced Beattie-Bridgeman, $C_{v}-\mathrm{C}_{v}^{\circ}=1.5 R$. So far as experimental data are available for checking, values of $C_{v}-C_{v}^{\circ}$ calculated from these equations of state appear to be too low, and we may expect that when better equations of state are found they will lead to higher values.

The value of $C_{v}-C_{v}^{\circ}$ found for oxygen from figure 6 is $5 R$, as compared with experimental values of $3.1 R$ for $\mathrm{CO}_{2}$ and $1.5 R$ for ethylene. Although the value of $5 R$ is not so far out of line as to be impossible, it is considerably larger than might be expected. The heat capacities well below the maxima in the curves are also rather higher than was expected, as is discussed in the following paragraph. Such results could be explained by assuming that the tare heat capacity was incorrectly determined, or that the heat leak changed between the gross and the tare measurements. However, the error required is larger than would be anticipated.

As previously pointed out, the heat capacities plotted in figure 6 are given by eq 3 . By evaluating and subtracting the last term in this equation, the molar heat capacity $C_{c}$ of saturated liquid can be obtained. This was done for each of the curves at $130^{\circ} \mathrm{K}$, using for the excess entropy the expression $S^{\prime}=(d P / d T)\left[V-\left(M-M_{t}\right) v_{c}\right]$ from reference [27]. Molar volumes of saturated liquid were taken from reference [11], and values of $d P / d T$ were calculated from table 2 . The values of $C$ read from the six curves of figure 6 at $130^{\circ} \mathrm{K}$ are (from bottom to top) 172, 130, 126, 123, 115, 100 $\mathrm{j} \mathrm{mole}^{-1} \mathrm{deg}^{-1}$. The corresponding values of $C_{c}$ found from eq 3 are in the same order 135, 108, $111,111,107,96 \mathrm{j} \mathrm{mole}^{-1} \mathrm{deg}^{-1}$. In the absence of error all these values should agree. Giving most weight to the values for which the correction was small, the data give a value of at least 100 $\mathrm{j}$ mole $^{-1} \mathrm{deg}^{-1}$ for saturated liquid at $130^{\circ} \mathrm{K}$. There are no other measurements at this temperature, but Giauque and Johnston [10] have reported heat capacities up to the boiling point $\left(90.19^{\circ} \mathrm{K}\right)$. At this temperature $C_{c}$ is about $54 \mathrm{j} \mathrm{mole}^{-1} \mathrm{deg}^{-1}$, and the curve is gradually rising. Compared with this, a value of 100 at $130^{\circ} \mathrm{K}$ seems rather high. One could of course postulate some cause of high heat capacity throughout the entire critical region, such as the existence of a large proportion of $\mathrm{O}_{4}$ molecules. Rather than draw any such conclusion, it seems wiser simply to present the data as a qualitative picture of the dependence of heat capacity on volume in the critical region. It is planned, when time permits, to perform similar experiments in an apparatus capable of normal calorimetric accuracy. The loss of helium from the resistance thermometer, which made it necessary to operate the apparatus with the space inside the shields filled with helium, also makes it seem unwise to repeat any of the calorimetric measurements with the present apparatus.

As a method of determining the critical temperature and volume, the calorimetric method appears to be comparable in ease of application with the isotherm method. It may be slightly inferior in accuracy with equal expenditure of effort. Before it can be practically applied, a better knowledge of the relation between heatcapacity curves and isotherms is needed. At present the exact point on the critical heatcapacity curve to associate with the point on the critical isotherm having a horizontal tangent is not known. From figure 6 one would say that at the critical temperature $C_{v}$ has fallen somewhat more than half way from its maximum to its limiting value.

\section{The Critical Constants}

The critical constants derived from the isotherm data (fig. 5) are $T_{c}=154.78^{\circ} \pm 0.03^{\circ} \mathrm{K}, p_{c}=$ $50.14 \pm 0.07 \mathrm{~atm}$, and $\rho_{c}=0.38 \mathrm{~g} \mathrm{~cm}^{-3}$. Of these, $T_{c}$ and $p_{c}$ are probably better values than any previously available. The value of $\rho_{c}$ is much less accurate. There do not appear to be any reported measurements of the critical constants of $\mathrm{O}_{2}$ since the survey of Pickering [34] in 1926, which summarized the results of 11 different investigations in which one or more of the critical constants was determined. Pickering selected as best values: $t_{c}=-118.8^{\circ} \mathrm{C}, p_{c}=49.7 \mathrm{~atm}$, and $\rho_{c}=0.430 \mathrm{~g} \mathrm{~cm}^{-3}$. These are also the values contributed by Germann and Pickering to the International Critical Tables [24]. They are essentially the values of Onnes, Dorsman, and Holst [4] for $T_{c}$ and $p_{c}$, and the value of Mathias and Onnes [35] for $\rho_{c}$. In the original paper Onnes, Dorsman, and Holst give $T_{c}$ both in centigrade and Kelvin units $\left(-118.82^{\circ} \mathrm{C}=\right.$ 
$154.27^{\circ} \mathrm{K}$ ). They determined the critical temperature by observing the formation of a meniscus when the sample was suddenly expanded by a small amount. If the meniscus remained permanently the temperature was considered to be below $T_{c}$. At the accepted value of $T_{c}$ the meniscus appeared in the middle of the tube: then slowly disappeared at the same level. The critical density was found by Mathias and Onnes by extrapolation of the rectilinear diameter of the density parabola.

The critical pressure now being reported is $0.43 \mathrm{~atm}$ higher than the value of Onnes et al. $(49.713 \mathrm{~atm})$. The critical temperature is 0.51 deg higher. One may ask whether this is simply the result of using different methods of identifying the critical point, as it is common experience that the meniscus disappears somewhat below the highest temperature for which $(\partial p / \partial v)_{T}=0$. If this were the case the values $154.27^{\circ} \mathrm{K}$ and 49.713 atm would satisfy table 2 , being simply a slightly lower point on the vapor-pressure curve than the critical point now being reported. Figure 4 shows that less than half the discrepancy can be explained in this way. The highest plotted point in figure 4 is the critical point of Onnes, Dorsman, and Holst. It is about $0.29 \mathrm{deg}$ lower than the table. This discrepancy must be due either to actual differences in temperature or pressure measurements or to the purity of the sample.

The value of the critical density deduced from the isotherm measurements $\left(0.38 \mathrm{~g} \mathrm{~cm}^{-3}\right)$ is probably less accurate than the value of Mathias and Onnes (0.4299). ${ }^{7}$

\section{The Two Solid-Solid Transitions}

One heat-capacity run extending from $20.4^{\circ} \mathrm{K}$ to above the triple point of $0_{2}$ was made in 1942 , with the small conventional adiabatic calorimeter. No tare run was made, and the mass of $\mathrm{O}_{2}$ was only approximately known, so no specific heats or heats of transition are reported. The shape of the heat-capacity curve at the lower transition is shown in figure 8 . The upper curve was obtained first, proceeding from lower to higher temperatures as indicated by the arrows. Then the apparatus was left for about an hour, with the shields cold

\footnotetext{
' Since completing this paper, the apparatus has been used on another project. The measurements of volumes occupied by fluid at high pressure, discussed on p. 336 , have been repeated and extended. The redeterminations confirm the value $\rho_{c}=0.38 \mathrm{~g} \mathrm{~cm}^{-3}$, and it is now thought that this value should have equal weight with that of Mathias and Onnes.
}

so that the $0_{2}$ cooled partially through the transition again. On resuming measurements from this condition a much lower heat capacity curve was obtained in the transition region. This is presumably due to hysteresis in the transition and would not have been observed if the second cooling had proceeded to $20.4^{\circ} \mathrm{K}$ like the first. The maximum in the first heat-capacity curve is at $23.886^{\circ} \pm 0.005^{\circ} \mathrm{K}$.

Table 6 contains the previously reported values for the temperature of this transition and also for the temperature of the transition at $43.8^{\circ} \mathrm{K}$. The table also contains the more recent reported

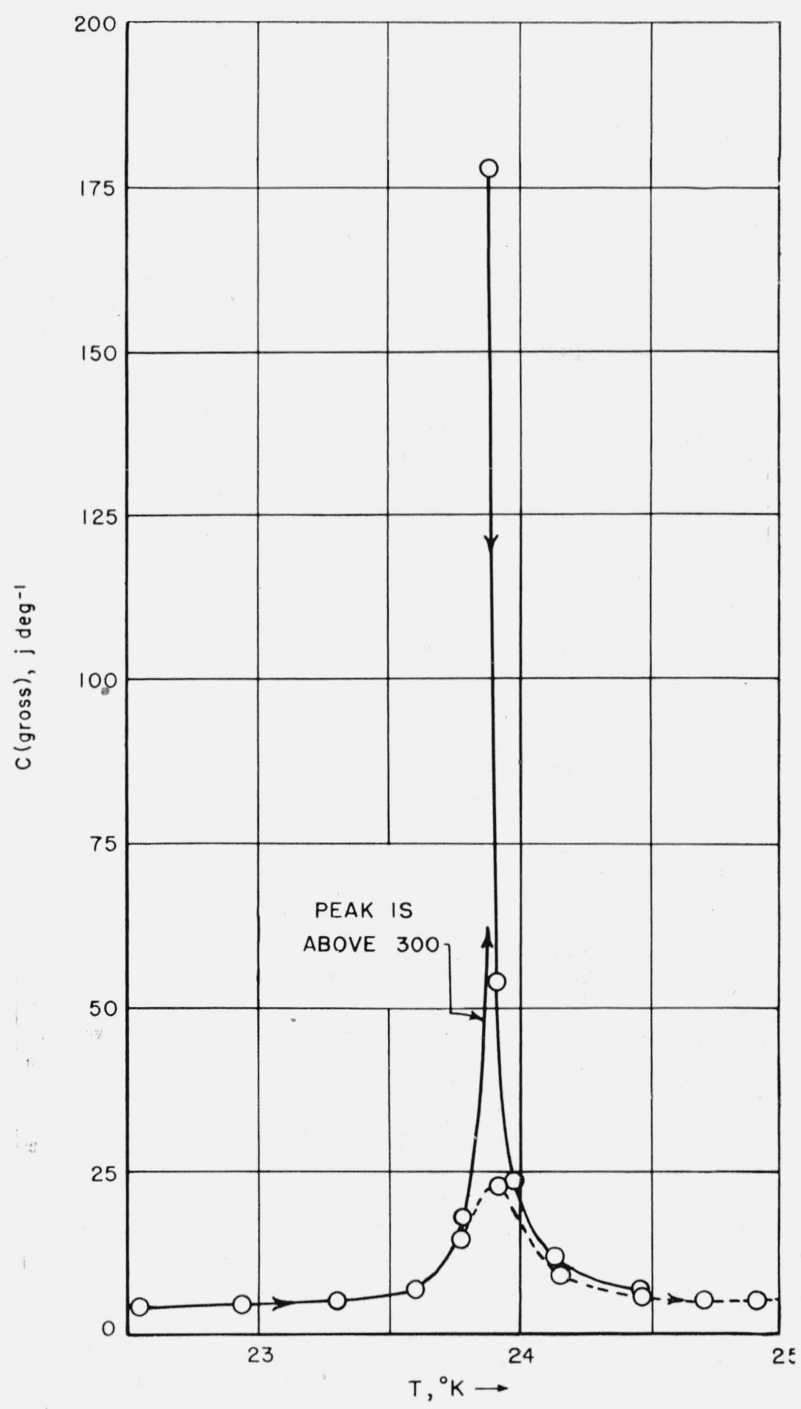

FIGURE 8. Heat capacity of oxygen in the neighborhood of $23.9^{\circ} \mathrm{K}$.

Solid curve obtained in the usual way; dotted curve obtained after cooling only part way through the transition. 
TABLE 6. Some previously reported values of the transition temperatures, the triple-point temperature and pressure, and the normal boiling point of oxygen

\begin{tabular}{|c|c|c|c|c|}
\hline Year & Reference & $T$ & $p$ & Thermometer \\
\hline \multicolumn{5}{|c|}{ TRANSITION AT $23.9^{\circ} \mathrm{K}$} \\
\hline & & ${ }^{\circ} K$ & $\begin{array}{c}m m \\
H g\end{array}$ & \\
\hline 1916 & Eucken $[36]$ & 23.5 & -. & $\mathrm{Pb}$ resistance \\
\hline 1929 & Clusius [37] $\ldots .$. & 23.8 & .. & $\mathrm{Pb}$ resistance \\
\hline 1929 & $\begin{array}{l}\text { Giauque and Johnston } \\
{[10]}\end{array}$ & 23. 66 & - & Cu-const thermel \\
\hline 1949 & This research & 23. 886 & -. & Pt resistance \\
\hline \multicolumn{5}{|c|}{ TRANSITION AT $43.8^{\circ} \mathrm{K}$} \\
\hline 1916 & Eucken $[36] \ldots \ldots$ & 42.5 & -. & $\mathrm{Pb}$ resistance \\
\hline 1929 & Clusius $[37] \ldots \ldots$ & 43.5 & -- & $\mathrm{Pb}$ resistance \\
\hline 1929 & $\begin{array}{l}\text { Giauque and Johnston } \\
\text { [10] }\end{array}$ & 43. 76 & - & Cu-const thermel \\
\hline 1935 & Aoyama and Kanda [18]. & 43. 70 & -- & Cu-const thermel \\
\hline 1949 & This research & $43.80_{0}$ & -. & Pt resistance \\
\hline \multicolumn{5}{|c|}{ TRIPLE POINT } \\
\hline 1911 & $\begin{array}{l}\text { Onnes and Crommelin } \\
{[38]}\end{array}$ & a 54.7 & -. & Pt resistance \\
\hline 1911 & Dewar $[39] \ldots$ & 54 & 1.12 & $\mathrm{H}_{2}$ gas \\
\hline 1916 & Eucken $[36] \ldots$ & 54.1 & -- & $\mathrm{Pb}$ resistance \\
\hline 1929 & Clusius [37] $\ldots$ & 54.1 & -- & $\mathrm{Pb}$ resistance \\
\hline 1929 & $\begin{array}{l}\text { Giauque and Johnston } \\
{[10]}\end{array}$ & 54.39 & -- & Cu-const thermel \\
\hline 1931 & Justi [40] & 54. 24 & 1. 20 & Resistance \\
\hline 1935 & Aoyama and Kanda [18] & $54.4_{0}$ & -. & $\mathrm{Cu}$-const thermel \\
\hline 1935 & Lisman and Keesom [41]. & $54.32_{5}$ & -- & Pt resistance \\
\hline 1936 & Henning and Otto [20] & 54.33 & -- & He gas const volume \\
\hline 1949 & This research & 54. 363 & 1. 14 & Pt resistance \\
\hline \multicolumn{5}{|c|}{ BOILING POINT } \\
\hline 1918 & Cath [15] & 90.14 & $\cdots$ & He gas const volume \\
\hline 1924 & Henning and Heuse [16]. & b 90.196 & $-\ldots$ & He gas const volume \\
\hline 1927 & Henning [42] ........... & b 90.21 & $\ldots$ & $\mathrm{Pt}$ resistance \\
\hline 1929 & $\begin{array}{l}\text { Giauque and Johnston } \\
{[10]}\end{array}$ & 90.13 & $\cdots$ & Cu-const thermel \\
\hline 1929 & $\begin{array}{l}\text { Keesom, Van der Horst, } \\
\text { and Jansen [43] }\end{array}$ & $\bullet 90.143$ & --- & He gas const volume \\
\hline 1931 & Heuse and Otto $[44] \ldots$ & d 90.198 & $\cdots$ & He gas const volume \\
\hline 1932 & Heuse and Otto $[45] \ldots$ & d 90.195 & -..- & He gas const volume \\
\hline 1935 & Aoyama and Kanda [46]. & d 90.18 & $\ldots$ & $\mathrm{H}_{2}$ gas const volume \\
\hline 1935 & $\begin{array}{l}\text { Keesom and Dammers } \\
\text { [47] }\end{array}$ & е 90.159 & $-\ldots$ & Pt resistance \\
\hline 1937 & Blue and Hicks [48] $\ldots$ & 90.20 & $\ldots$ & He gas const volume \\
\hline \multicolumn{5}{|c|}{$\begin{array}{l}\text { d Using } \mathrm{T}_{0}=273.16 . \\
\text { e Using } \mathrm{T}_{0}=273.144 .\end{array}$} \\
\hline
\end{tabular}

values of the triple point temperature and pressure and the boiling point. Most of the references in table 6 are from a previous survey made by the author [22], which also contains some additional references published prior to 1915. Eucken [36] states that the $23.9^{\circ} \mathrm{K}$ transition showed time lags that made it difficult to measure the heat of transition accurately. Clusius [37] says the transition is sharp, but Giauque and Johnston [10] found temperature variations of $0.1 \mathrm{deg}$ while the transition varied from 15 to 65 percent complete. In the present experiments the transition was found to be rather broad, but no very noticeable tendency for the temperature to drift after heating periods was observed. This was in contrast to the behavior at the $43.8^{\circ} \mathrm{K}$ transition, where the tendency to drift was extreme.

The transition at $43.8^{\circ} \mathrm{K}$ is more satisfactorily represented by a temperature versus energy curve than by a heat-capacity curve. Figure 9 shows the gradual rise in temperature as successive portions of the sample were transformed. After each addition of energy the temperature drifted down rapidly at first and then more and more slowly. The temperature was plotted versus time for these drifts, to see whether the limiting value was independent of the amount of material converted. This was quite definitely not the case. The waiting periods were not all the same length. The high points in figure 9 correspond to short waiting periods and the low points to long waiting periods. The line drawn through the points corresponds roughly to an average drift period of $10 \mathrm{~min}$. By waiting longer the whole curve would have been lowered and might have lost some of its upward slope, but could certainly not have been made flat. Figure 9 gives $43.81_{0}^{\circ} \mathrm{K}$ as the temperature when the transition is half completed. With much longer drift periods this value might have been lowered to about $43.80_{0}^{\circ} \mathrm{K}$. The latter value is included in table 6 as the best value of the transi-

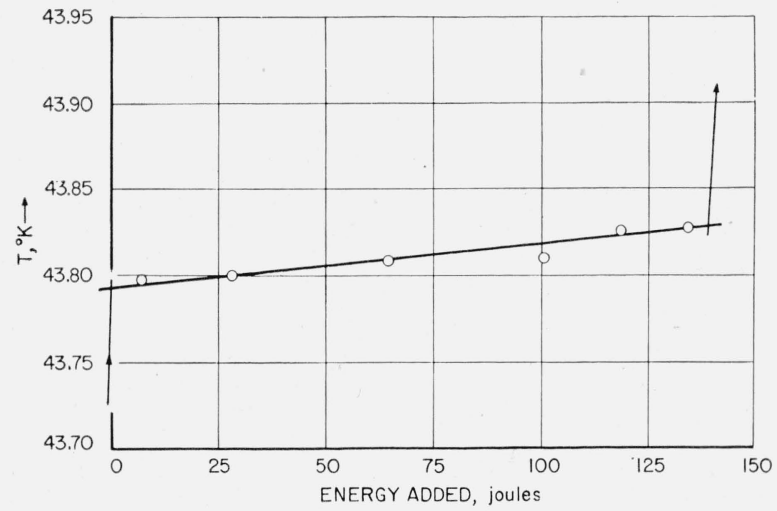

Figure 9. Temperature versus energy curve for oxygen in the neighborhood of $43.8^{\circ} \mathrm{K}$, showing that the transition covers a temperature interval of more than $0.03 \mathrm{deg}$. 
tion temperature derivable from the present work.

It is of interest that the heat of transition at $43.8^{\circ} \mathrm{K}$ is larger than the heat of fusion (at $54.363^{\circ}$ $\mathrm{K})$, in the ratio of 5 to 3 . This transition is generally assumed to be due to a change in crystal structure. The heat of the transition at $23.9^{\circ} \mathrm{K}$ is about one-fifth of the heat of fusion. It has been suggested that this transition is of magnetic origin. The curve in figure 8 bears some resemblance to those that are commonly attributed to the onset of rotation of the molecules of a crystal lattice, but is somewhat more symmetrical than the typical curve of this type. Perrier and Onnes [49] found that on cooling from $33^{\circ}$ to $20^{\circ} \mathrm{K}$, the magnetic susceptibility of $\mathrm{O}_{2}$ suddently drops to about half its original value. Although they thought the change occurred near $33^{\circ} \mathrm{K}$ it is more likely that it took place at the $23.9^{\circ} \mathrm{K}$ transition.

\section{The Triple Point and the Boiling Point}

The plotting of melting-point data versus the reciprocal of $F$, the fraction of the sample melted, was discussed in the section on preparation and purity of the samples. The intercept of the straight line drawn gives the triple point of pure material. Measurements on the first sample, made with platinum resistance thermometer L3, gave a triple point temperature of $54.363^{\circ} \mathrm{K}$. Similar measurements on the third sample, made with thermometer L14 gave a value less than 1 mdeg lower. Such close agreement is fortuitous, for L14 was calibrated by comparison with some of the group of standard thermometers of which L3 was a member, and the comparison could be expected to introduce uncertainties of 2 or $3 \mathrm{mdeg}$.

Several observations of the triple-point pressure are given in table 1 . The last of these is the most reliable. Earlier points may possibly be in error because of condensation in the tube leading to the manometer. For previously reported values of triple-point temperatures and pressure, table 6 should be consulted.

The temperature of the normal boiling point of $\mathrm{O}_{2}$ was taken to be $90.19^{\circ} \mathrm{K}$. This is the value obtained when the accepted value on the ITS $\left(-182.97^{\circ} \mathrm{C}\right)$ is converted to the Kelvin scale with $\mathrm{T}_{0}=273.16^{\circ} \mathrm{K}$. The calibration of the resistance thermometers was based on this value and hence the present data yield no information on its correctness. This value has been used in all our work since and including the establishment of the NBS provisional temperature scale below $90^{\circ} \mathrm{K}$. Some of the more recent reported values of the boiling point are given in table 6 .

\section{Remarks on Temperature Scales}

No correlation of vapor-pressure data with latent heat data is presented at this time. It is known that the ITS and the provisional scale below $90.19^{\circ} \mathrm{K}$ on which these measurements are reported (PTS) are not in exact agreement with the thermodynamic scale. This is particularly true near the point where the PTS and the ITS join. The quantity $d\left(\log _{10} p\right) / d(1 / T)$ was computed

TABLE 7. Fixed-point temperatures reported by three different laboratories, selected for a comparison of temperature scales

Values in parentheses are accepted values rather than original determinations

\begin{tabular}{|c|c|c|c|c|c|}
\hline Fixed point & PTR & NBS & California & $\begin{array}{c}\text { PTR } \\
\text {-Calif. }\end{array}$ & $\begin{array}{l}\text { NBS } \\
\text {-Calif. }\end{array}$ \\
\hline $\mathrm{n}-\mathrm{H}_{2}$ triple point & $\begin{array}{rr}{ }^{\circ} K & \\
13.96 & {[20]}\end{array}$ & $\begin{array}{c}{ }^{\circ} K \\
13.96[1]\end{array}$ & $\begin{array}{r}\circ K \\
13.92\end{array}$ & $\begin{array}{r}\text { mdeg } \\
40\end{array}$ & $\begin{array}{l}\text { mdeg } \\
\quad 40\end{array}$ \\
\hline $\mathrm{n}-\mathrm{H}_{2}$ boiling point & $(2.380)[20]$ & 20.39 [1] & 20.36 & 20 & 30 \\
\hline $\mathrm{O}_{2}$ upper trans... & - & $43.80_{0}$ & 43. $76[10]$ & & 40 \\
\hline $\mathrm{O}_{2}$ triple point $\ldots .$. & $54.33 \quad[20]$ & 54. 363 & $54.39[10]$ & -60 & -27 \\
\hline $\mathrm{N}_{2}$ triple point $\ldots$ & $63.14 \quad[20]$ & & $63.14[50]$ & 0 & \\
\hline $\mathrm{N}_{2}$ boiling point & $77.352[20]$ & ( & $77.32[50]$ & 32 & \\
\hline $\mathrm{O}_{2}$ boiling point & a 90.195 [45] & $(90.19)$ & $90.13[10]$ & 65 & 60 \\
\hline
\end{tabular}

a Using $\mathrm{T}_{0}=273.16^{\circ} \mathrm{K}$,

from table 2 by numerical differentiation. It exhibited noticeable irregularities that are undoubtedly due to irregularities in the temperature scale. Our temperature scale could undoubtedly be improved simply by smoothing the curve of $d\left(\log _{10} p\right) / d(1 / T)$ and computing the corresponding changes in temperatures, but it seems best not to include such an investigation in the present paper. By use of Clapeyron's equation it is easily shown that

$$
-\frac{d\left(\log _{10} p\right)}{d(1 / T)}=\frac{L}{2.303 R\left(Z_{g}-Z_{l}\right)}
$$

where $L$ is the heat of vaporization, and the $Z$ 's are compressibility factors $(Z=P V / R T)$ for the gas and the liquid phases, respectively. Experimental determination of $L$ on the same temperature scale as the vapor pressure measurements would permit a much more significant correlation of vapor pressures and latent heats than is now possible, and would permit our temperature scale to be more accurately smoothed. It is planned to undertake measurements of the heat of vaporization as soon as time permits. 


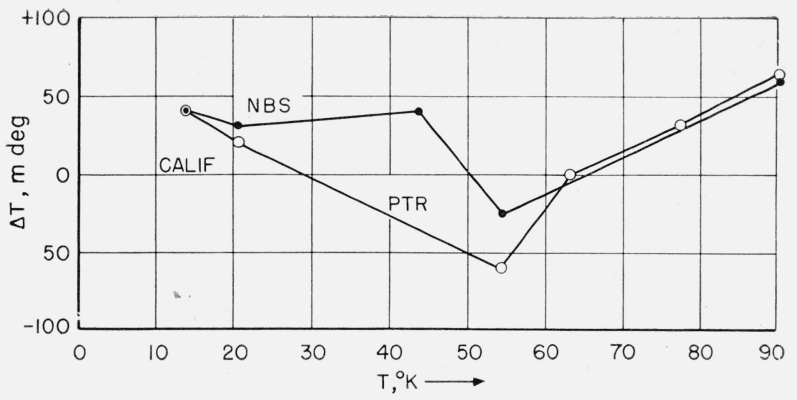

Figure 10. A comparison of the temperature scales of three different laboratories by means of the fixed-point data of table $\%$.

Certain laboratories, such as the Leiden Laboratory, the Physikalisch-Technische Reichsanstalt (PTR), the cryogenic laboratory of Professor Giauque at the University of California, and the National Bureau of Standards, have maintained and used more or less well defined temperature scales over periods of years. As the temperatures of various fixed points on these scales are published it becomes possible to compare them. Table 7 contains a few data of this sort from three of the laboratories mentioned. Differences in the reported values for each fixed point are plotted in figure 10, using the California scale as a base line because it contains all of the fixed points included. The figure shows that the P'TR and NBS values are in somewhat better agreement with each other than with the California data. The comparison of vapor-pressure data given in figure 4 is, as previously pointed out, essentially a comparison of temperature scales. Judging from this figure, temperatures between $60^{\circ}$ and $90^{\circ} \mathrm{K}$ are uncertain by at least $30 \mathrm{mdeg}$; and slopes, which determine the accuracy of heat capacity measurements, may be uncertain by a part in 300 .

Russell B. Scott collaborated in all the measurements made in 1942. Thanks are due also to a number of persons who have assisted in the subsequent work, particularly Ruth (Cheney) Suits, Robert E. McCoskey, and Martin T. Wechsler. The drawings and graphs were prepared by W. L. Cross, Jr.

\section{References}

[1] Harold J. Hoge and Ferdinand G. Brickwedde, Establishment of a temperature scale for the calibration of thermometers between $14^{\circ}$ and $83^{\circ} \mathrm{K}$, J. Research NBS 22, 351 (1939) RP1188.
[2] H. F. Stimson, The International Temperature Scale of 1948, J. Research NBS 42, 209 (1949) RP1962.

[3] Barnett F. Dodge and Harvey N. Davis, Vapor pressure of liquid oxygen and nitrogen, J. Am. Chem. Soc. 49, 610 (1927).

[4] H. Kamerlingh Onnes, C. Dorsman, and G. Holst, Vapor pressures of oxygen and critical point of oxygen and nitrogen, Commun. Phys. Lab. Univ. Leiden 145b (1914).

[5] Russell B. Scott, Cyril H. Meyers, Robert D. Rands, Jr., Ferdinand G. Brickwedde, and Norman Bekkedahl, Thermodynamic properties of 1,3butadiene in the solid, liquid, and vapor states, J. Research NBS, 35, 39 (1945) RP1661.

[6] N. S. Osborne, H. F. Stimson, E. F. Fiock, and D. C. Ginnings, The pressure of saturated water vapor in the range $100^{\circ}$ to $374^{\circ} \mathrm{C}$, BS J. Research 10, 155 (1933) RP523.

[7] C. H. Meyers and R. S. Jessup, A multiple manometer and piston gages for precision measurements, BS J. Research 6, 1061 (1931) RP324

[8] D. F. Stedman, Pıeliminary survey of the fractionation of isotopic isomers by distillation, Can. J. Research [B] 13, 114 (1935).

[9] Russell B. Scott, The calibration of thermocouples at low temperatures. Temperature-its measurement and control in science and industry, p. 206 to 218 (Reinhold Pub. Corp., New York, N. Y., 1941).

[10] W. F. Giauque and H. L. Johnston, The heat capacity of oxygen from $12^{\circ} \mathrm{K}$ to its boiling point and its heat of vaporization. The entropy from spectroscopic data, J. Am. Chem. Soc. 51, 2300 (1929).

[11] Russell W. Millar and John D. Sullivan, Thermodynamic properties of oxygen and nitrogen, U. S. Bureau of Mines Technical Paper 424 (1928).

[12] Raymond T. Birge, The general physical constants, Reports on Progress in Physics 8, 90 (1941).

[13] R. S. Jessup, Compressibility and thermal expansion of petroleum oils in the range $0^{\circ}$ to $300^{\circ} \mathrm{C}, \mathrm{BS} \mathrm{J}$. Research 5, 985 (1930) RP244.

[14] H. v. Siemens, On vapor pressure measurements and thermometry at low temperatures, Ann. Physik. 42, 871 (1913).

[15] P. G. Cath, Vapor pressures of oxygen and nitrogen for obtaining fixed points on the temperature scale below $0^{\circ} \mathrm{C}$, Commun. Phys. Lab. Univ. Leiden 152d (1918).

[16] F. Henning and W. Heuse, A new determination of the normal boiling points of oxygen, nitrogen, and hydrogen, Zeit. Physik. 23105 (1924).

[17] W. F. Giauque, H. L. Johnston, and K. K. Kelley, Hydrogen gas thermometer compared with the oxygen and hydrogen vapor-pressure thermometers by means of a copper-constantan thermocouple, J. Am. Chem. Soc. 49, 2367 (1927).

[18] Shinichi Aoyama and Eizo Kanda, The vapor tensions of oxygen and nitrogen in the solid state, Sci. Repts. Tohoku Imp. Univ. Sendai 24, 107 (1935). 
[19] J. G. Aston, Eugene Willihnganz, and George H. Messerly, A thermodynamic temperature scale in terms of the copper-constantan thermocouple from $12^{\circ}$ to $273^{\circ}$ K, J. Am. Chem. Soc. 5\%, 1642 (1935).

[20] F. Henning and J. Otto, Vapor-pressure curves and triple points in the temperature range from $14^{\circ}$ to $90^{\circ}$ abs., Phys. Zeit. 37, 633 (1936).

[21] Daniel R. Stull, Vapor pressures of pure substances, Ind. Eng. Chem. 39, 517 (1947).

[22] Harold J. Hoge, A practical temperature scale below the oxygen point and a survey of fixed points in this range. Temperature-its measurement and control in science and industry, p. 141 to 156 (Reinhold Pub. Corp., New York, 1941).

[23] American Petroleum Institute Research Project 44 at the National Bureau of Standards. Selected Values of Properties of Hydrocarbons. Table No. la-Paraffins, $\mathrm{C}_{1}$ to $\mathrm{C}_{5}$. Boiling point, $d t / d p$, refractive index, density and freezing point. (June 30, 1945; June 30, 1948).

[24] International Critical Tables 3, 248 (1928).

[25] A. Michels, B. Blaisse, and C. Nichels, The isotherms of $\mathrm{CO}_{2}$ in the neighborhood of the critical point and round the coexistence line, Proc. Roy. Soc. London [A]160, 358 (1937).

[26] Harold J. Hoge, Cyril H. Meyers, and Robert E. McCoskey, Charts of compressibility factors and charts showing quantities delivered by commercial cylinders for hydrogen, nitrogen, and oxygen, NBS Misc. Pub. M191 (1948).

[27] Harold J. Hoge, Heat capacity of a two-phase system, with applications to vapor corrections in calorimetry, J. Research NBS 36, 111 (1946) RP1693.

[28] Harold W. Woolley, Thermodynamic functions for molecular oxygen in the ideal gas state, J. Research NBS 40, 163 (1948).

[29] K. Bennewitz and E. Splittgerber, Specific heat of carbon dioxide at the critical point, Zeit. physikal. Chem. 124, 49 (1926).

[30] A. Michels and S. R. de Groot, Thermodynamical properties of carbon dioxide as function of density and temperature, Appl. Sci. Research A1, 94 (1948).

[31] Serge Gratch, Zero-pressure thermodynamic properties of carbon dioxide. Presented at the annual meeting of the Am. Soc. Mech. Engrs. (New York, N. Y., Nov. 28 to Dec. 3, 1948).

[32] D. B. Pall, J. W. Broughton, and O. Maass, The heat capacity at constant volume of the system ethylene near the critical temperature and pressure, Can. J. Research B16, 230 (1938).

[33] American Petroleum Institute Research Project 44 at the National Bureau of Standards. Selected Values of the Properties of Hydrocarbons. Table No. 8v (Part 1) Monoolefins, $\mathrm{C}_{2}$ to $\mathrm{C}_{4}$, Heat Capacity, $C_{p}^{\circ}$, for the ideal gas state, at $0^{\circ}$ to $1500^{\circ} \mathrm{K}$ (Dec. 31, 1944; April 30, 1946).

[34] S. F. Pickering, A review of the literature relating to the critical constants of various gases, BS Sci. Pap. 21, 597 (1926) S541.
[35] E. Mathias and H. Kamerlingh Onnes, The rectilinear diameter for oxygen, Commun. Phys. Lab. Univ. Leiden 11 (1911).

[36] A. Eucken, On the thermal behavior of some compressed and condensed gases at low temperatures, Verhandl. deut. physik. Ges. 18, 4 (1916).

[37] Klaus Clusius, On the specific heats of some condensed gases between $10^{\circ}$ abs. and their triple points, Zeit. physikal. Chem. B3, 41 (1929).

[38] H. Kamerlingh Onnes and C. A. Crommelin, Remarks upon the critical temperature of neon and upon the melting point of oxygen, Commun. Phys. Lab. Univ. Leiden 121c (1911).

[39] James Dewar, Production of solid oxygen by the evaporation of the liquid, Proc. Roy. Soc. London [A] 85, 589 (1911).

[40] E. Justi, On the triple points of nitrogen and oxygen as fixed points of the temperature scale, Ann. Physik 10, 983 (1931).

[41] J. H. C. Lisman and W. H. Keesom, The melting curve of oxygen to $170 \mathrm{~kg} / \mathrm{cm}^{2}$, Commun. Kamerling Onnes Lab. Univ. Leiden 239a (1935).

[42] F. Henning, Vapor pressure and resistance thermometers in the temperature regions of liquid nitrogen and hydrogen, Zeit. Physik 40, 775 (1927).

[43] W. H. Keesom, H. van der Horst, and A. F. J. Jansen, New determination of the normal boiling point of oxygen, Commun. Phys. Lab. Univ. Leiden $\mathbf{2 0 3 b}$ (1929).

[44] W. Heuse and J. Otto, A new gas-thermometric determination of fixed points below $0^{\circ}$ in connection with vapor-pressure and resistance thermometers, Ann. Physik. 9, 486 (1931).

[45] W. Heuse and J. Otto, Gas thermometric determination of some fixed points below $0^{\circ}$, with vaporpressure and resistance thermometers. II, Ann. Physik 14, 185 (1932).

[46] Shinichi Aoyama and Eizo Kanda, Determination of fixed points in the low termperature with a hydrogen thermometer, Bull. Chem. Soc. Japan 10, 472 (1935).

[47] W. H. Keesom and B. G. Dammers, On the construction of platinum resistance thermometers and the determination of their basic points, Commun. Kamerlingh Onnes Lab. Univ. Leiden R39d (1935).

[48] R. W. Blue and J. F. G. Hicks, Jr., Comparison of platinum-rhodium resistance thermometers with the helium gas thermometer from $11^{\circ}$ to $300^{\circ} \mathrm{K}$. An improved cryostat, J. Am. Chem. Soc. 59, 1962 (1937).

[49] Albert Perrier and H. Kamerlingh Onnes, The susceptibility of liquid mixtures of oxygen and nitrogen, and the influence of the mutual distances of the molecules upon paramagnetism, Commun. Phys. Lab. Univ. Leiden 139d (1914).

[50] W. F. Giauque and J. O. Clayton, Heat capacity and entropy of nitrogen. Heat of vaporization. Vapor pressures of solid and liquid. The reaction $1 / 2 \mathrm{~N}_{2}+$ $1 / 20_{2}=\mathrm{NO}$ from spectroscopic data, J. Am. Chem. Soc. 55, 4875 (1933).

Washington, September 26, 1949. 